\title{
Experimental Investigation and Model Development for Thermal Conductivity of $\alpha-\mathrm{Al}_{2} \mathrm{O}_{3}$-Glycerol Nanofluids
}

\author{
M. Sharifpur ${ }^{1 *}$, N. Tshimanga ${ }^{1}$, J. P. Meyer ${ }^{1}$ and O. Manca ${ }^{2}$ \\ ${ }^{1}$ Nanofluids Research Laboratory, Department of Mechanical and Aeronautical Engineering \\ University of Pretoria, Private Box 0002, Pretoria, South Africa \\ ${ }^{2}$ Department of Industrial and Information Engineering, \\ Università degli Studi della Campania "Luigi Vanvitelli", via Roma 29, 81031 Aversa, Italy
}

\begin{abstract}
In order to investigate the effect of nanoparticle volume fraction, nanoparticle size and temperature on the thermal conductivity of glycerol based alumina $\left(\alpha-\mathrm{Al}_{2} \mathrm{O}_{3}\right)$ nanofluids, a set of experiments were carried out for temperature ranging from $20{ }^{\circ} \mathrm{C}$ to $45{ }^{\circ} \mathrm{C}$. The nanofluids contained $\alpha-\mathrm{Al}_{2} \mathrm{O}_{3}$ nanoparticles of three different sizes $(31 \mathrm{~nm}, 55 \mathrm{~nm}$ and $134 \mathrm{~nm})$ were prepared by two-step method at volume fractions ranging from $0.5 \%$ to $4 \%$. The experimental results show that $\alpha-\mathrm{Al}_{2} \mathrm{O}_{3}$-glycerol nanofluids have substantially higher thermal conductivity than the base fluid and the maximum enhancement of the relative thermal conductivity was $19.5 \%$ for the case of $31 \mathrm{~nm}$ at $4 \%$ volume fraction. The data analyses indicated that the volume fraction and size of the nanoparticles have significant effects on the thermal conductivity ratio (TCR) of $\mathrm{Al}_{2} \mathrm{O}_{3}$-glycerol nanofluids, while the temperature has almost no significant effect on the data for range of this study. At room temperature, the effective thermal conductivity remains almost constant for 50 hours at $4 \%$ volume fractions. The comparison of the obtained experimental data and predictions from some existing theoretical and empirical models reveals that the thermal conductivity ratio and its trend could not be accurately explained by the models in open literature. Consequently, a new empirical correlation based on the experimental data has been developed in this study.
\end{abstract}

Keywords: Nanofluids, glycerol, thermal conductivity, volume fraction, alumina.

\footnotetext{
*Corresponding author: Prof. Mohsen Sharifpur
}

Tel: +27 124202448 Email: mohsen.sharifpur@up.ac.za 


\section{Nomenclature}

$A_{p} \quad$ Projected area of nanoparticle, $\mathrm{m}^{2}$

circ Circularity

$c_{p} \quad$ Specific heat, J/kg.K

$d \quad$ Diameter, $\mathrm{m}$

D Einstein diffusion coefficient

F F-statistic

$h \quad$ Non-locality characteristic length, $m$

$\hbar \quad$ Ratio, $\quad \hbar=\frac{r}{h}$

$k \quad$ Thermal conductivity, $\mathrm{W} / \mathrm{mK}$

$K \quad$ A shape factor

$p \quad$ p-value

$P \quad$ Outline perimeter of nanoparticle, $\mathrm{m}$

$\mathrm{Pr} \quad$ Prandtl number

$r \quad$ Radius, $\mathrm{m}$

$R \quad$ Coefficient of correlation

Re Reynolds number

SSA Specific surface area, $\mathrm{m}^{2}$

$T$ Temperature, ${ }^{\circ} \mathrm{C}$

$t \quad$ Time, $\mathrm{s}$

$t_{v, p} \quad$ Weighing function for $v$ degree of freedom and $\mathrm{p} \%$ of probability

$u \quad$ Uncertainty

$u_{B} \quad$ Bias error

$u_{p} \quad$ Precision or random error

wt. Weight fraction of the species

$W \quad$ Weight, $\mathrm{kg}$

Greek symbols

$\beta \quad$ Full-width at half maximum, rad

$\varepsilon \quad$ Fraction of liquid volume that travels with a nanoparticle

$\theta \quad$ Diffraction angle, rad

$\kappa \quad$ Boltzmann's constant, $\mathrm{J} / \mathrm{K}$

$\lambda \quad \mathrm{X}$-ray wavelength, $\AA$

$\mu \quad$ Viscosity, N.s $/ \mathrm{m}^{2}$

$v \quad$ Velocity, $\mathrm{m} / \mathrm{s}$ 
$\Im$ Ratio, $\mathfrak{\Im} 1=\frac{1}{\hbar}+\arctan (\hbar)-\frac{\pi}{2}$

$\Im 2 \quad$ Ratio, $\Im 2=\arctan (\hbar)+\frac{\hbar}{1+\hbar^{2}}+\frac{8 \hbar}{\left(1+\hbar^{2}\right)^{2}}+\frac{8 \hbar^{3}}{\left(1+\hbar^{2}\right)^{3}}-\frac{\pi}{2}$

$\rho \quad$ Density, $\mathrm{kg} / \mathrm{m}^{3}$

$\sigma_{1} \quad$ Ratio, $\sigma_{1}=\left(1+\frac{\delta}{r_{p}}\right)$

$\sigma_{2} \quad$ Ratio, $\sigma_{2}=\left(1+\frac{\delta}{2 r_{p}}\right)$

$\tau_{D} \quad$ Time necessary for nanoparticle of diameter $\mathrm{d}_{\mathrm{p}}$ to cover the distance equal to its size, $\mathrm{s}$

$\phi \quad$ Volume fraction

Subscripts

$\begin{array}{ll}\text { B } & \text { Brownian } \\ \text { cryst } & \text { Crystallite } \\ \text { eff } & \text { Effective } \\ f & \text { Fluid } \\ f r & \text { Freezing point of the base liquid } \\ g l y & \text { Glycerol } \\ p & \text { Particle } \\ T C R & \text { Thermal conductivity ratio } \\ 10 & 10 \% \text { of nanoparticles have diameter less than } \\ 50 & \text { Mean of particle diameter distribution } \\ 90 & 90 \% \text { of nanoparticles have diameter less than }\end{array}$

\section{Introduction}

The importance of heat transfer fluids with high thermal conductivity than conventional ones has been noted by many scientists and engineers since they improve the heat removal efficiency in heating or cooling systems. Experiments have shown that the suspended nanoparticles or nanofibers, viz. $\mathrm{Cu}$, $\mathrm{MgO}, \mathrm{CuO}, \mathrm{Al}_{2} \mathrm{O}_{3}, \mathrm{TiO}_{2}, \mathrm{SiO}_{2}, \mathrm{SiC}, \mathrm{ZnO}$, graphene, carbon nanotube (CNT), multiwalled carbon nanotube (MWCNT) improve the transport and thermal properties of conventional fluids [1-8]. Experimental studies reveal the dependence of thermal conductivity ratio (TCR) of nanofluids on nanoparticles volume fraction, particles size, temperature, amount and type of surfactants, thermal conductivity of base fluid, thermal conductivity and size of nanolayer, aggregation, sedimentation time and $\mathrm{pH}$ of nanofluids. Numbers of experimental study [1,9-11] have investigated the thermal conductivity of Alumina $\left(\mathrm{Al}_{2} \mathrm{O}_{3}\right)$ nanoparticles prepared with different based fluids such as water, ethylene glycol, mixtures of ethylene glycol (EG) and water, oil, and methanol. 
Recently, Ghanbarpour et al. [10] observed that the thermal conductivity of water based $\mathrm{Al}_{2} \mathrm{O}_{3}$ nanofluids increases non-linearly with nanoparticle concentration, but linearly with a rise of temperature. The nanoparticle of spherical shape and average size of about $75 \mathrm{~nm}$ was investigated. The thermal conductivity enhancements were reported in the range of $1.1 \%$ to $87 \%$ at mass concentration ranging from $3 \%$ to $50 \%$ and temperature range of $20{ }^{\circ} \mathrm{C}$ to $50{ }^{\circ} \mathrm{C}$. Mostafizur et al. [1] also measured the thermal conductivity of three different methanol based nanofluids for temperature ranging from $1{ }^{\circ} \mathrm{C}$ to $20{ }^{\circ} \mathrm{C}$ and volume fraction range of $0.005 \%$ to $0.15 \%$. The sonication at frequency and power of $50 \mathrm{~Hz}$ and $500 \mathrm{~W}$, respectively were used for two hours to improve the dispersion of the mixture of $\mathrm{Al}_{2} \mathrm{O}_{3}$-methanol, $\mathrm{SiO}_{2}$-methanol and $\mathrm{TiO}_{2}$-methanol nanofluids with average particles diameter of 13, 5-15 and $21 \mathrm{~nm}$, respectively. They found that the thermal conductivity of the nanofluids increased with a rise of nanoparticle volume fraction and temperature. $\mathrm{Al}_{2} \mathrm{O}_{3}$ nanoparticles dispersed in methanol gave greater enhancement of thermal conductivity than $\mathrm{SiO}_{2}$ and $\mathrm{TiO}_{2}$ nanoparticles, for the volume fraction range of $0.005 \%$ to $0.15 \%$. At $20{ }^{\circ} \mathrm{C}$, for $0.15 \%$ volume fraction of $\mathrm{Al}_{2} \mathrm{O}_{3}, \mathrm{SiO}_{2}$ and $\mathrm{TiO}_{2}$ nanoparticles, the thermal conductivity enhancement was $29.41 \%, 23.033 \%$ and $24.51 \%$ respectively.

Application of glycerol as anti-freeze in automotive applications is being examined by ASTM International Committee D15 [12]. In 1930's, glycerol was used as an anti-freeze before to be replaced by ethylene glycol due to cost considerations. Ethylene glycol is used as an anti-freeze for a wide variety of mechanical equipment during winter times to prevent freezing of aqueous heat-transfer fluids. Since 2004, there is a surplus production of glycerol from biodiesel in the global market. This situation could be favourable to make the glycerol cost effective as antifreeze. Glycerol is more environmental friendly than ethylene glycol. Moreover, it can remain fluid at low temperatures and resist to oxidation than oil. Glycerol is recommended when there is a contact with lubricant in food pharmaceutical, cosmetic manufacture and where mineral oils as lubricant are less recommended for oxygen compressor, pumps and bearings exposed to fluids such as gasoline and benzene [13].

There is a lack of information of $\alpha-\mathrm{Al}_{2} \mathrm{O}_{3}$-glycerol nanofluids thermal conductivity in the literature. Therefore, this investigation is aimed to determine experimentally the impact of the nanoparticle volume fraction, particle diameter, temperature on the thermal conductivity of stable $\alpha-\mathrm{Al}_{2} \mathrm{O}_{3}$-glycerol nanofluids. Additionally, the measured dataset were compared with the values predicted by some theoretical and empirical models of thermal conductivity of nanofluids, which may work for glycerol base nanofluids. Consequently, a new correlation of thermal conductivity of $\alpha-\mathrm{Al}_{2} \mathrm{O}_{3}$-glycerol nanofluids is developed.

\section{Material and Methods}

\subsection{Materials}

Three $\alpha-\mathrm{Al}_{2} \mathrm{O}_{3}$ nanoparticles of different diameters were analyzed in this work, which the manufacturer clam were $40 \mathrm{~nm}(\mathrm{~S} 1), 80 \mathrm{~nm}(\mathrm{~S} 2)$ and $100 \mathrm{~nm}$ (S3). The $\alpha-\mathrm{Al}_{2} \mathrm{O}_{3}$ nano- powder of 80 
$\mathrm{nm}$ was purchased from US Research Nanomaterials, Inc. (Houston, TX, USA). The $40 \mathrm{~nm}$ and 100 $\mathrm{nm}$ nanoparticles were procured from MK Nano, Inc. (Mississauga, ON, Canada). The glycerol (base fluid) was supplied by Merck Millipore (Darmstadt, Germany). Table 1 presents the physicochemical properties of the selected nanoparticles [14-16].

Table 1: Properties of $\mathrm{Al}_{2} \mathrm{O}_{3}$ nanoparticles

\begin{tabular}{|c|c|c|c|c|c|c|}
\hline Item & $\begin{array}{c}\text { Diameter } \\
(\mathbf{n m})\end{array}$ & $\begin{array}{c}\text { Purity } \\
(\%)\end{array}$ & Crystalline & Morphology & $\begin{array}{c}\text { True Density } \\
\left(\mathrm{g} / \mathrm{cm}^{3}\right) \text { at } 20^{\circ} \mathrm{C}\end{array}$ & $\begin{array}{c}\text { Thermal } \\
\text { conductivity } \\
(\mathrm{W} / \mathbf{m K})\end{array}$ \\
\hline & & & & nearly & & \\
\hline $\mathrm{Al}_{2} \mathrm{O}_{3}$ & 40 & 99.5 & alpha & $\begin{array}{c}\text { spherical } \\
\text { nearly }\end{array}$ & 3,7 & 40 \\
\hline $\mathrm{Al}_{2} \mathrm{O}_{3}$ & 80 & $99+$ & alpha & $\begin{array}{c}\text { spherical } \\
\text { nearly }\end{array}$ & $3.5-3.9$ & 40 \\
\hline $\mathrm{Al}_{2} \mathrm{O}_{3}$ & 100 & 99.9 & alpha & spherical & 3,7 & 40 \\
\hline
\end{tabular}

\subsection{Physical characterization of nanoparticles}

The physical characterisation of the $\alpha-\mathrm{Al}_{2} \mathrm{O}_{3}$ nanoparticles were evaluated by using the $\mathrm{X}$-ray Fluorescence Spectroscopy (XRF), X-ray powder Diffraction and the combined XRD and XRF, respectively. The XRF analyses were performed using an ARL 9400XP spectrometer. The XRD analysis of the prepared samples of $\alpha-\mathrm{Al}_{2} \mathrm{O}_{3}$ nanoparticles samples was carried out on a PANanalytical X'Pert Pro powder diffractometer with Co-K $\alpha$ radiation source $(\lambda=1.78901 \AA)$ at $50 \mathrm{kV}$ and current of $50 \mathrm{~mA}$. The results were recorded over a $2 \theta$ range of $10-90^{\circ}$ with a scanning rate of $0.02^{\circ} / \mathrm{s}$. Transmission Electron Microscopy (TEM) analysis of the samples was performed using JEM 2100F (JEOL, USA) to evaluate the shape and the size of particles. The JEM 2100F works with an accelerating voltage of $200 \mathrm{kV}$ in the range of $50 \mathrm{~V}$ min at variable steps of $2 \mathrm{ppm} / \mathrm{min}$. The JEM 2100F achieves the highest TEM images quality with point image resolution at $0.23 \mathrm{~nm}$ accuracy [17]. The TEM samples were prepared by dispersing the $\alpha-\mathrm{Al}_{2} \mathrm{O}_{3}$ nano-powder in acetone, followed by ultrasonication of 5 minutes. TEM image files were analysed using ImageJ software (NIH, Bethesda, MD, USA).

\subsection{Thermal conductivity measurement}

The thermal conductivity of both glycerol and $\alpha-\mathrm{Al}_{2} \mathrm{O}_{3}$-Glycerol nanofluid were measured with the KD2 Pro Thermal Properties Analyzer (Decagon device, USA). The handled device measure the thermal conductivity values ranging from 0.02 to $2 \mathrm{~W} / \mathrm{mK}$ over the temperature range of $0{ }^{\circ} \mathrm{C}$ to $50{ }^{\circ} \mathrm{C}$ with $5 \%$ accuracy [18]. It works based on the transient short hot-wire source method. Several 
researchers used successively the KD2 Pro [1, 19, 20]. The KD2 pro thermal analyser complies with both ASTM D5334 standard and IEEE 442-1981 regulations.

\subsection{Preparation of nanofluids}

The $\alpha-\mathrm{Al}_{2} \mathrm{O}_{3}$-glycerol nanofluids were prepared in a $100 \mathrm{ml}$ beaker with no surfactant for the volume fractions ranging from $0.5 \%$ to $4 \%$. The nanofluid was ultrasonicated with S14 sonotrod (UP200S Hielscher of 200 Watts operated at $24 \mathrm{kHz}$ ) [21] for two hours to ensure uniform dispersion of the nanoparticles. A thermal bath (LAUDA ECO RE1225 Silver) was used to obtain and/or maintain different temperatures of nanofluids during the measurement process. After that, the nanofluids were kept still for 30 minutes to minimize the forced convection produced by both ultrasonicator probe and the thermal bath. The thermal bath LAUDA works in the temperature range from $-5^{\circ} \mathrm{C}$ and $200^{\circ} \mathrm{C}$ at a minimum ambient temperature of $5^{\circ} \mathrm{C}$. It operates with a pump of maximum flow of $22 \mathrm{~L} / \mathrm{min}$ and maximum pressure of 0.55 bar. A pump of maximum flow runs the heat transfer fluid in the thermal bath to maintain the required temperature of the nanofluid. The bath can contain a heat transfer fluid at minimum and maximum capacity of 9.3L and 12L, respectively [22]. Figure 1 shows the experimental set-up for thermal conductivity measurement.

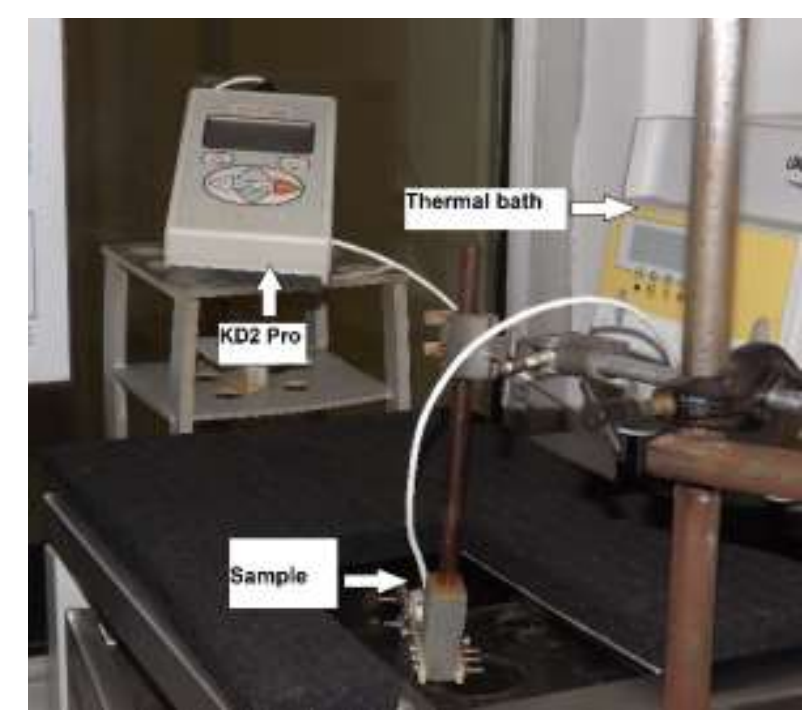

Figure 1: Experimental set-up for thermal conductivity measurement

The volume fraction of nanoparticles $(\phi)$ was determined using Eq. (1):

$\phi=\frac{\frac{W_{p}}{\rho_{p}}}{\frac{W_{p}}{\rho_{p}}+\frac{W_{g l y}}{\rho_{g l y}}} * 100 \%$

where $W_{p}, W_{g l y}, \rho_{p}$ and $\rho_{\text {gly }}$ are the weight of $\alpha-\mathrm{Al}_{2} \mathrm{O}_{3}$ nanoparticles, the weight of glycerol, the density of $\alpha-\mathrm{Al}_{2} \mathrm{O}_{3}$ nanoparticles and the density of glycerol, respectively. The nanoparticles, weighted by Adam electronic balance (model HCB1002), whose accuracy is $0.01 \mathrm{~g}$, were dispersed into the preweighed quantity of the base fluid. 


\subsection{Validation of experimental data}

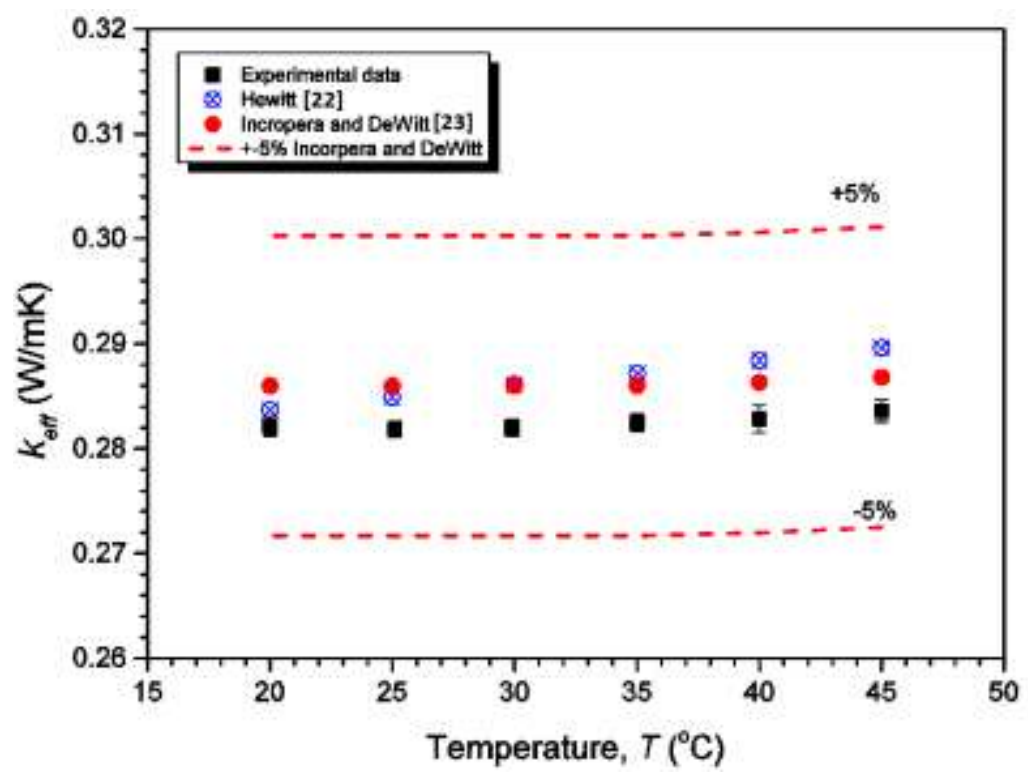

Figure 2 shows the values of thermal conductivity of glycerol measured with the KD2 Pro and the reference data for temperatures ranging from $20{ }^{\circ} \mathrm{C}$ to $45{ }^{\circ} \mathrm{C}[23,24]$. The reference values show a deviation of less than $1 \%$ between them. Each experimental data represents an average of nine measurements at various temperature. The results indicate that the measured data are in excellent agreement with available reference data, within $\pm 2 \%$ accuracy.

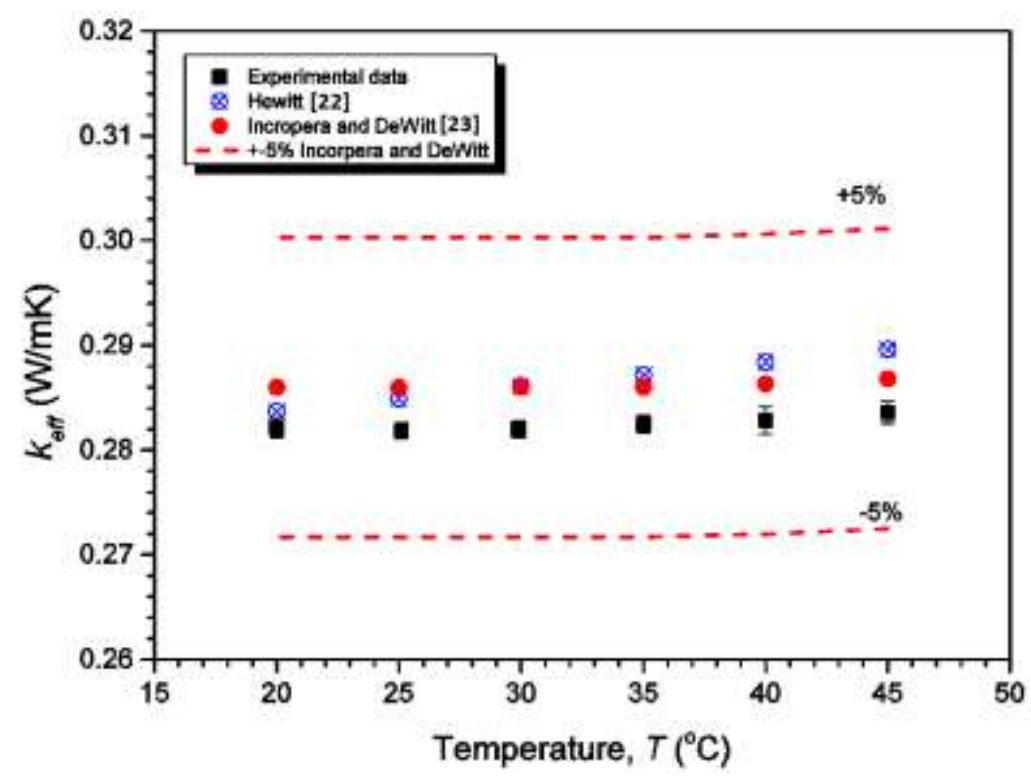

Figure 2 : Validation of experimental data

\section{Results and Discussion}

\subsection{Sample characterization}

Figure 3 shows the TEM images of the three samples of $\alpha-\mathrm{Al}_{2} \mathrm{O}_{3}$ nanoparticles. Figure 4 (a) shows the particle size distribution of the $\alpha-\mathrm{Al}_{2} \mathrm{O}_{3}$ nanoparticles determined using ImageJ software. The particle 
size distribution is based on the TEM image analysis of more than 500 particles, which were individually counted.

(a)

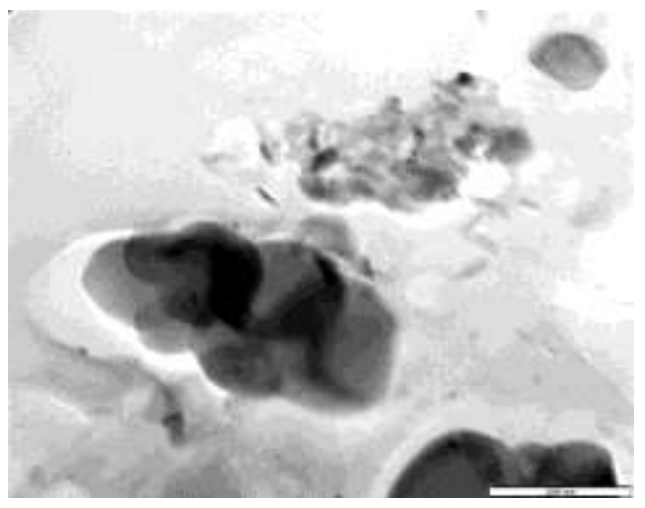

(b)

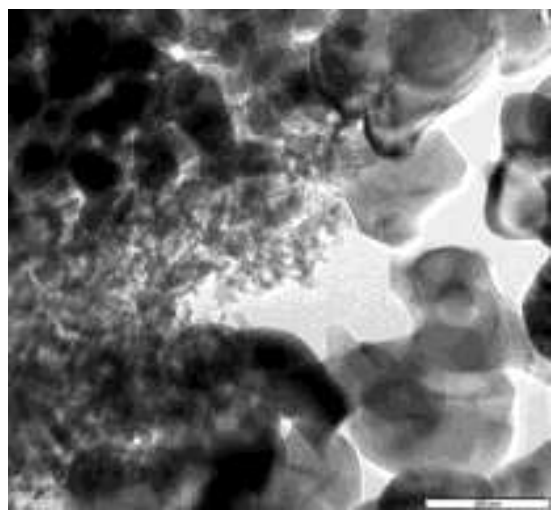

(c)

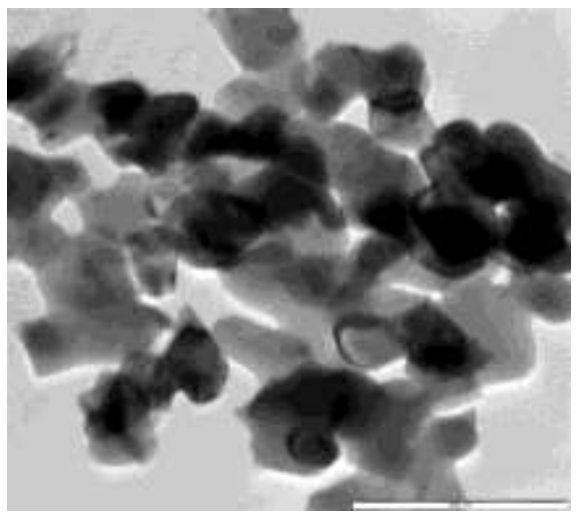

Figure 3: TEM image of $\alpha-\mathrm{Al}_{2} \mathrm{O}_{3}$ nanoparticles (a) $31 \mathrm{~nm}$, (b) $55 \mathrm{~nm}$ and (c) $134 \mathrm{~nm}$
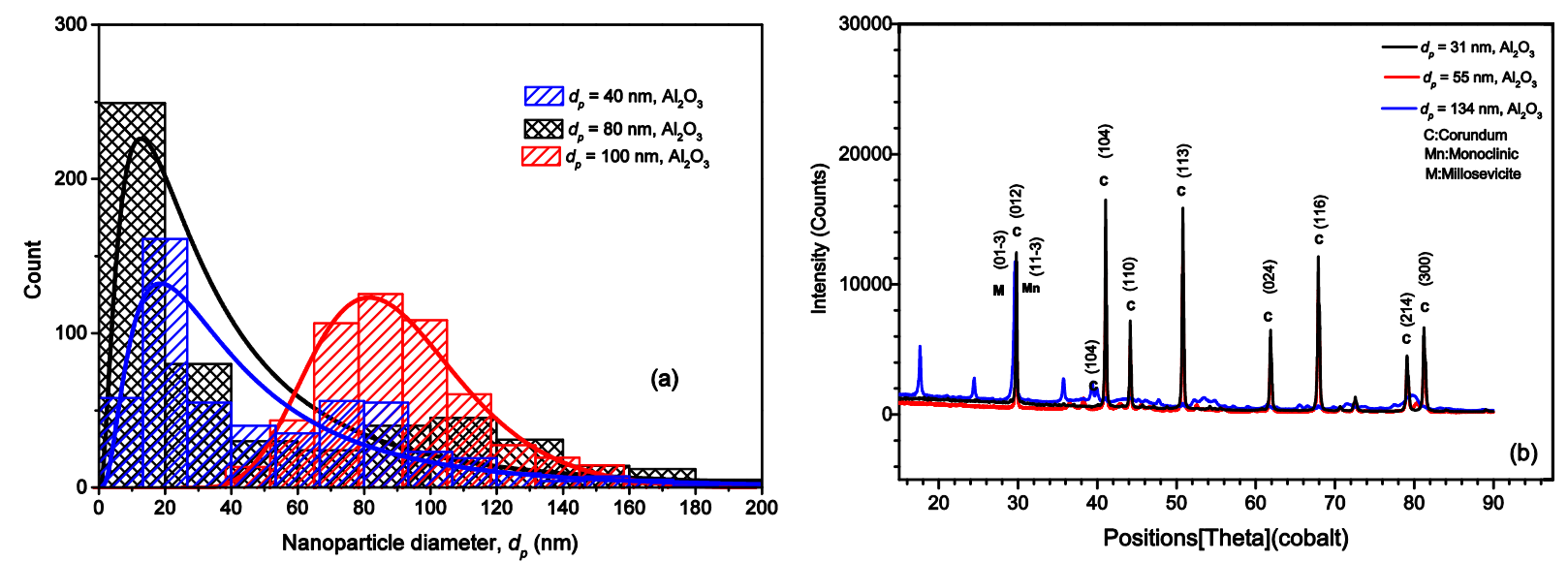

Figure 4: (a) Diameter distribution of $\alpha-\mathrm{Al}_{2} \mathrm{O}_{3}$ nanoparticles (b) X-ray diffraction pattern of the $\alpha-\mathrm{Al}_{2} \mathrm{O}_{3}$ nanoparticles powder

Both samples 1 and 2 show two prominent peaks bimodal data, each of its own with a separate central tendency while the sample S3 reveals an unimodal data distribution. The three $\alpha-\mathrm{Al}_{2} \mathrm{O}_{3}$ nanoparticles show a positive skewed size distribution, in the range of $19 \mathrm{~nm}\left(d_{10}\right), 54 \mathrm{~nm}\left(d_{50}\right)$ and $155 \mathrm{~nm}\left(d_{90}\right)$ for the $40 \mathrm{~nm}, 12 \mathrm{~nm}\left(d_{10}\right), 21 \mathrm{~nm}\left(d_{50}\right)$ and $127 \mathrm{~nm}\left(d_{90}\right)$ for the $80 \mathrm{~nm}$ and $97 \mathrm{~nm}\left(d_{10}\right), 134 \mathrm{~nm}\left(d_{50}\right)$ and $187 \mathrm{~nm}\left(d_{90}\right)$ for the $100 \mathrm{~nm}$, respectively [25, 26]. However, all the three nanoparticles respect the 
lognormal distribution with the mean particle size respectively of $55 \pm 2 \mathrm{~nm}$ for $\mathrm{S} 1,31 \pm 3 \mathrm{~nm}$ for S2 and $134 \pm 1 \mathrm{~nm} \mathrm{S3}$. There are significant differences in nanoparticles sizes between the obtained values and manufacture values. The situation may happen due to the unexpected event that can occur in the nanoparticle manufacturing process. As the manufacturer does not do the nanoparticle TEM analysis batch by batch to ascertain the size of produced nanoparticle. In this work, the obtained sizes are considered for further analyses i.e. $31 \mathrm{~nm}, 55 \mathrm{~nm}$ and $134 \mathrm{~nm}$, respectively. Eq. (2) defines the circularity parameter ( $\operatorname{circ}$ ). The circularity of 1 and approaching 0 refers to the perfect circle and increasingly elongated shape object respectively [27].

$\operatorname{circ}=4 \pi\left(\frac{A_{p}}{P}\right)^{2}$

where $A_{p}$ and $P$ are the projected area and outside perimeter of the outline of the nanoparticle respectively.

The circularity of $31 \mathrm{~nm}, 55 \mathrm{~nm}$ and $134 \mathrm{~nm} \alpha-\mathrm{Al}_{2} \mathrm{O}_{3}$ nanoparticles are equal to 0.9 . Thus, our nanoparticles have a shape close to the sphere than that of elongated shape object.

Figure 4 (b) shows XRD patterns of $\alpha-\mathrm{Al}_{2} \mathrm{O}_{3}$ nanoparticles. The patterns are in good agreement with the standard diffraction data of two types of $\mathrm{Al}_{2} \mathrm{O}_{3}$ defined by the International Center for Diffraction Data (ICDD) database. The first one is Rho53

mbohedral system of Corundum $\left(\mathrm{Al}_{2} \mathrm{O}_{3}\right)$ of Powder Diffraction Patterns with PDF file No. 01-0897717 and the second Monoclinic $\mathrm{Al}_{2} \mathrm{O}_{3}$ (PDF file No. 01-086-1410) for $40 \mathrm{~nm}$, a Rhombohedral system of Corundum $\left(\mathrm{Al}_{2} \mathrm{O}_{3}\right)$ of PDF file No. 98-008-8029 for $80 \mathrm{~nm}$ and both Rhombohedral Corundum (PDF file No. 01-081-2267) and Rhombohedral Millosevichite ( $\mathrm{Al}_{2}\left[\mathrm{SO}_{4}\right]_{3}$ of PDF file No. 01-077-0066 for $100 \mathrm{~nm}$.

The mineralogical analysis confirms that both samples of S1 and S3 consist of a mixture of Corundum and Millosevichite, while S2 is composed of Corundum (Table 2 and Table 3). The crystallite size was estimated using Scherer equation (3). The equation (3) predicts at best $\pm 10 \%$ the crystallite size which the assumption of $K=1$ is considered [28].

$d_{\text {cryst }}=\frac{K \lambda}{\beta \cos \theta}$

where $K$ is the shape factor varying from 0.62 to $2.08, \lambda$ is the wavelength of $\mathrm{X}$-ray source, $\beta$ is the peak width of the profile at Full Half Maximum Height (FWHM) of crystallite size and $\theta$ is the diffraction angle expressed in radian. 
Table 2: Chemical composition of $\alpha-\mathrm{Al}_{2} \mathrm{O}_{3}$ nanoparticles

\begin{tabular}{|c|c|c|c|c|c|c|c|c|c|}
\hline Diameter & $\mathbf{A l}_{2} \mathbf{O}_{3}$ & $\mathrm{SiO}_{2}$ & $\mathrm{TiO}_{2}$ & $\mathrm{Fe}_{2} \mathrm{O}_{3}$ & $\mathrm{MgO}$ & $\mathrm{CaO}$ & $\mathrm{Na}_{2} \mathrm{O}$ & $\mathbf{P}_{2} \mathbf{O}_{5}$ & LOI* \\
\hline 40 & 99.7 & 0.02 & 0.00 & 0.04 & 0.16 & 0.01 & 0.02 & 0.02 & 0.3 \\
\hline 80 & 99.88 & 0.02 & 0.36 & 0.06 & 0.2 & 0.01 & 0.02 & 0.09 & 0.40 \\
\hline 100 & 74.28 & 0.02 & 0.03 & 0.05 & 0.13 & 0.01 & 0.05 & 0.02 & 26.86 \\
\hline
\end{tabular}

The values of $K$ are 0.89 and 0.94 for a spherical particle with cubic symmetry crystallites determined by integral breadth and FWHM, respectively $[29,30]$. $K$ can take an approximate value of one in both situations [31]. The average crystalline sizes are $38.0 \mathrm{~nm}$ for the $33 \mathrm{~nm} \alpha-\mathrm{Al}_{2} \mathrm{O}_{3}, 48.4 \mathrm{~nm}$ for $55 \mathrm{~nm} \alpha$ $\mathrm{Al}_{2} \mathrm{O}_{3}$ and $35.4 \mathrm{~nm}$ for $134 \mathrm{~nm} \alpha-\mathrm{Al}_{2} \mathrm{O}_{3}$ nanoparticles, respectively. However, the calculation has been done without correction for instrumental, stress broadening and any other possible sources of line broadening.

Table 3: Mineralogical composition of $\alpha-\mathrm{Al}_{2} \mathrm{O}_{3}$ nanoparticles

\begin{tabular}{|c|c|c|c|c|c|c|}
\hline \multirow{3}{*}{ Mineral } & \multicolumn{6}{|c|}{ Nanoparticles } \\
\hline & \multicolumn{2}{|c|}{$40 \mathrm{~nm} \alpha-\mathrm{Al}_{2} \mathrm{O}_{3}$} & \multicolumn{2}{|c|}{$80 \mathrm{~nm} \alpha-\mathrm{Al}_{2} \mathrm{O}_{3}$} & \multicolumn{2}{|c|}{$100 \mathrm{~nm} \alpha-\mathrm{Al}_{2} \mathrm{O}_{3}$} \\
\hline & Weight (\%) & $3 \mathrm{SD}$ & Weight (\%) & $3 \mathrm{SD}$ & Weight (\%) & $3 \mathrm{SD}$ \\
\hline \multicolumn{7}{|l|}{ Millosevichite } \\
\hline$\left(\mathrm{Al}_{2} \mathrm{SO}_{4}\right)$ & 19.5 & & 0 & 0 & - & \\
\hline Corundum $\left(\mathrm{Al}_{2} \mathrm{O}_{3}\right)$ & 80.5 & & 100 & 0 & - & \\
\hline
\end{tabular}

\subsection{Uncertainty calculation}

The uncertainty of experimental results was determined from both the bias error (instrument) and precision error resulting from the deviation in the experimental dataset. The bias error in measurement of thermal conductivity by KD2 Pro is 5\%. The accuracy of the weighing scale is $0.01 \mathrm{~g}$. The uncertainty of the experiment is obtained by the following [32]:

$u= \pm \sqrt{\left(u_{B}\right)^{2}+\left(u_{P}\right)^{2}}$

$$
\text { with } \quad u_{p}= \pm t_{v, p} S D
$$

where $u_{B}, u_{p}, t_{v, p}$ and $S D$ are bias error, precision or random error in measurement with $p \%$ probability, weighing function for $v$ degree of freedom and $p \%$ probability and sample standard deviation, respectively. The uncertainty in TCR $\left(u_{T C R}\right)$ is given as follow:

$u_{T C R}=\left[\left(\frac{\delta k_{e f f}}{k_{f}}\right)^{2}+\left(\frac{-k_{e f f}}{\left[k_{f}\right]^{2}} \delta k_{f}\right)^{2}\right]^{0.5}$ 
where $\delta k_{\text {eff }}$ and $\delta k_{f}$ are uncertainty at $p \%$ probability including both bias and precision errors associated with the measured effective thermal conductivity of nanofluids and thermal conductivity of nanofluids, respectively. Finally, the uncertainty in the effective thermal conductivity and TCR was found to be between $5.1 \%$ and $8.5 \%$.

\subsection{Experimental study of thermal conductivity}

\subsubsection{Introduction}

The impact of parameters is statistically analyzed based on 72 data of TCR variability. A linear regression analysis is performed in each of the following sections to evaluate the individual impact of each parameters on the TCR, assuming the other variables are held constant, whereas a multivariate analysis will be performed to calculate if the independent variables jointly can influence the TCR. The $\mathrm{F}$ and t-ratio tests are used to for regression analysis [33, 34].

\subsubsection{Effect of particle volume fraction and particle diameter}

Figure 5 shows the effect of particle volume fraction (at volume fractions of $0.5 \%, 1 \%, 2 \%$ and $4 \%$, respectively) on the effective thermal conductivity ratio of three sizes of $\alpha-\mathrm{Al}_{2} \mathrm{O}_{3}$-glycerol nanofluids at $20{ }^{\circ} \mathrm{C}$. The $\alpha-\mathrm{Al}_{2} \mathrm{O}_{3}$ nanoparticles dispersed in glycerol yielded higher thermal conductivity than the base fluid (glycerol). As it is obvious in the figure, effective thermal conductivity increases linearly with an increase of volume fraction for each particle size. A linear regression analysis is performed to determine the effect of volume fraction on the TCR. The equation (6) obtained has $\mathrm{R}^{2}$ of 0.822 and Fstatistic of the model is 322.8 which correspond to significance $p$ of 0.000 . It means that the model is statistically significant and $82.2 \%$ of the variability in the TCR values is explained by the model. The rest $(17.8 \%)$ of variation in TCR can be explained by residual and other variables.

$\frac{k_{e f f}}{k_{f}}=0.997+3.824 \phi$

where $\phi$ is the $\alpha-\mathrm{Al}_{2} \mathrm{O}_{3}$ nanoparticle volume fraction.

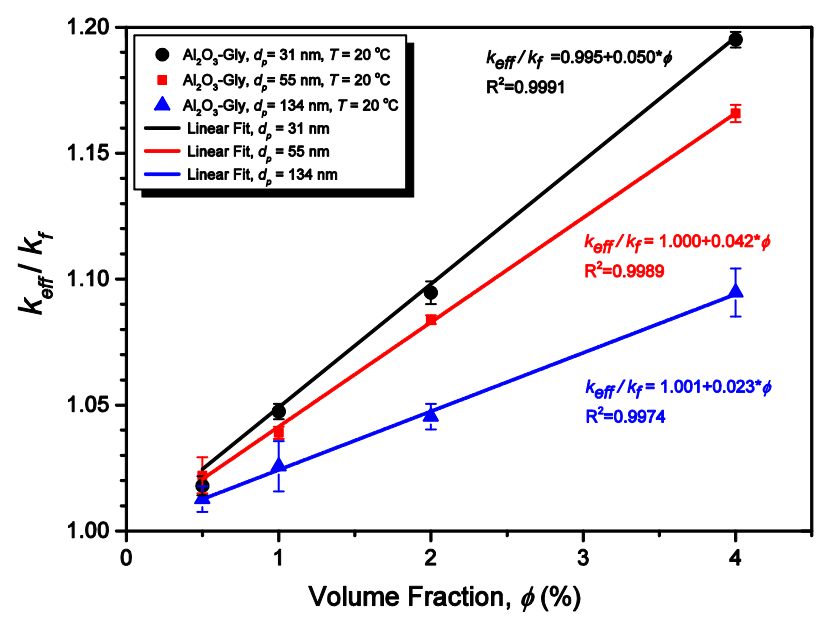

Figure 5: Influence of the Nanoparticle volume fraction on the thermal conductivity ratio of the three set of $\alpha$ - $\mathrm{Al}_{2} \mathrm{O}_{3}$-glycerol nanofluids at $20{ }^{\circ} \mathrm{C}$ 
There is a linear increase of TCR with increase of $\alpha-\mathrm{Al}_{2} \mathrm{O}_{3}$ nanoparticles volume fraction. This outcome is in agreement with other studies for various types of nanofluids [35-40]. The thermal conductivities ratio improved up to $19.5 \%, 16.6 \%$ and $9.5 \%$ at nanoparticle volume fraction of $4 \%$ for $31 \mathrm{~nm}, 55 \mathrm{~nm}$ and $134 \mathrm{~nm}$ size nanoparticles, respectively. Figure 5 clearly depicts the impact of particle size on the TCR. Smaller particles size lead to high thermal conductivity of nanofluids than the bigger ones. The same situation have been perceived at various range of temperature.

The estimated straight-line regression of TCR on diameter (size) is given by equation (7).

$\frac{k_{e f f}}{k_{f}}=1.0997-4.29 \times 10^{-4} d_{p}$

where $d_{p}$ is the particle diameter in $\mathrm{nm}$.

The equation (7) has $\mathrm{R}^{2}$ of 0.111 and the F-statistic of the model is 8.78 which correspond to significance $\mathrm{p}$ of $0.004(\mathrm{p}<0.05)$. It means that $11.1 \%$ of the variability in the TCR values is explained by the model. The rest (88.9\%) of variation in TCR can be explained by residual, volume fraction and other variables. The t-ratio of intercept and slope (diameter) are 88.816 and -2.963 , respectively. Their correspondent significant $\mathrm{p}$-values are 0.000 and $0.004(\mathrm{p}<0.05)$. Therefore, the model is statistically valid. The thermal conductivity ratio of $\alpha-\mathrm{Al}_{2} \mathrm{O}_{3}$-glycerol nanofluids increases with decreasing particle size for each volume fraction and temperature. These variation could be explained by the Brownian motion.

The improvement of thermal conductivity ratio in all the three nanofluids with respect to volume fraction could be possibly be explained by one or more mechanisms including Brownian motion, nanoparticles clustering, layering at the solid-liquid interface.The suspended $\alpha-\mathrm{Al}_{2} \mathrm{O}_{3}$ nanoparticles in the glycerol increase the surface area and the heat capacity of the glycerol, and both interaction and collision among $\alpha-\mathrm{Al}_{2} \mathrm{O}_{3}$ nanoparticles are strengthened [41, 42]. The Brownian diffusion coefficient $(D)$ is expressed by Einstein-stokes equation [43] as follow:

$D=\frac{\kappa T}{3 \pi \mu_{f} d_{p}}$

where $\kappa$ is the Boltzmann constant $(\mathrm{J} / \mathrm{K}), T$ is the temperature of the nanofluid $(\mathrm{K}), \mu_{f}$ is the viscosity of the base fluid (N/s.m $\mathrm{m}^{2}$ ) and $d_{p}$ is the nanoparticle diameter $(\mathrm{m})$.

Einstein-stoke equation (8) shows that the nanofluids prepared with smaller size nanoparticles will result in high $D$ coefficient than the one prepared with bigger size. Consequently, more severe collisions among nanoparticles and fluid molecules will be present in nanofluids which lead to better thermal conduction $[44,45]$. The increase of particle volume fraction decreases the distances between nanoparticles in nanofluids. This phenomenon associated with severe collision into nanofluids lead to better thermal conduction [41]. Moreover, smaller particles exhibit larger surface area to volume ratio 
than the bigger particles, which can possibly result in noticeable enhancement of the effective thermal conductivity [5].

\subsubsection{Effect of temperature}

Figure 6 (a) shows the effect of temperature on the effective thermal conductivity of $31 \mathrm{~nm} \alpha-\mathrm{Al}_{2} \mathrm{O}_{3^{-}}$glycerol nanofluids for three different sizes of nanoparticles. The results observed in Figure 6 (a) depict that the temperature dependence of the effective thermal conductivity of nanofluids tracks the base fluid (glycerol), but in another level of magnitude. Analogous results were observed for $55 \mathrm{~nm}$ and $134 \mathrm{~nm} \alpha-\mathrm{Al}_{2} \mathrm{O}_{3}$-glycerol nanofluids. Similar findings were reported for the $\mathrm{Al}_{2} \mathrm{O}_{3}$-water nanofluids [38], and Ethylene Glycol based nanofluids containing $\mathrm{Al}_{2} \mathrm{O}_{3}, \mathrm{MgO}, \mathrm{ZnO}, \mathrm{SiO}_{2}$, and graphene nanoparticles $[5,10,38,46]$.
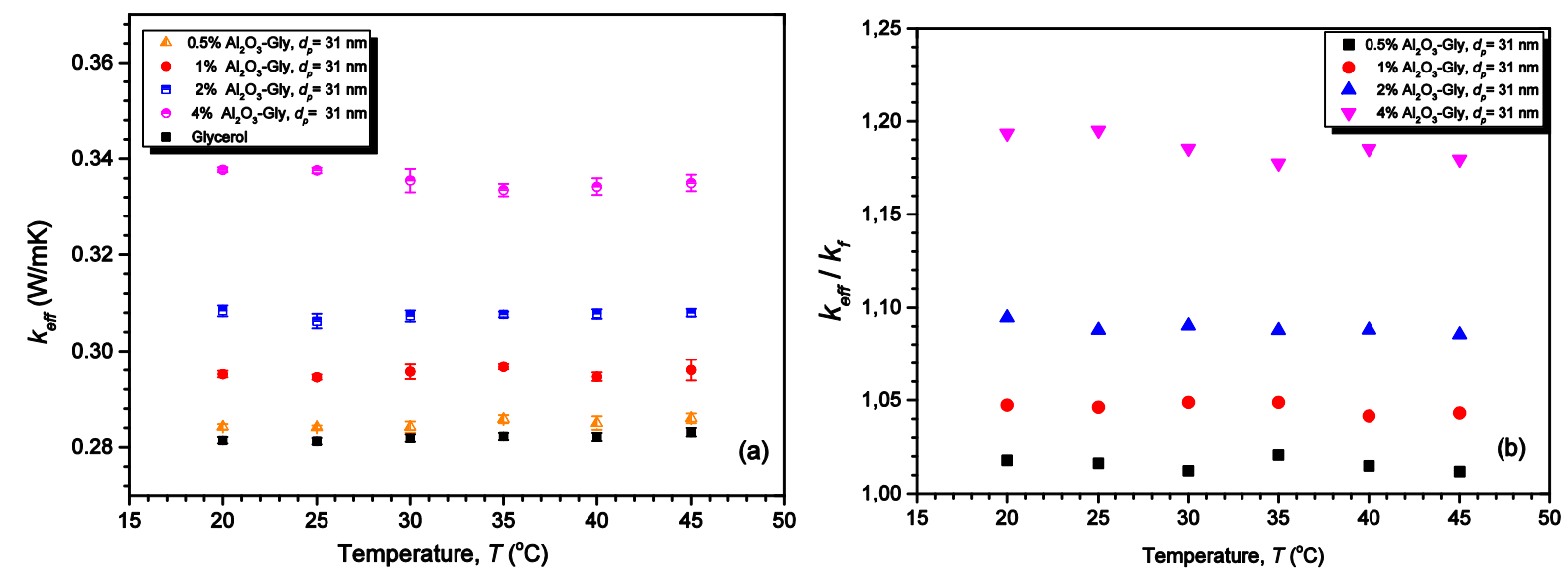

Figure 6: Temperature dependence of $31 \mathrm{~nm} \alpha-\mathrm{Al}_{2} \mathrm{O}_{3}$-glycerol nanofluids at different volume concentrations (a) Effective thermal conductivity (b) Thermal conductivity ratio

Figure 6 (b) shows the thermal conductivity ratio of $31 \mathrm{~nm} \alpha-\mathrm{Al}_{2} \mathrm{O}_{3}$-glycerol nanofluids at different volume fractions as function of temperature. The estimated line relationship between the temperature and the TCR computed is as follow.

$\frac{k_{e f f}}{k_{f}}=1.071-7.02 \times 10^{-5} \mathrm{~T}$

where $T$ is temperature expressed in ${ }^{\circ} \mathrm{C}$.

The obtained equation has unadjusted $\mathrm{R}^{2}=0.0001, \mathrm{~F}=0.01$ and significant $\mathrm{p}=0.930(\mathrm{p}>0.05)$; which is obviously greater than the significance level 0.05 . The t-ratio of intercept and slope (temperature) are 39.87 and -0.09 , respectively. Their correspondent significant $\mathrm{p}$ value are $0.000(\mathrm{p}<$ $0.05)$ and $0.930(\mathrm{p}>0.05)$. Thus, there is no significant dependence of TCR with temperature for the glycerol based $\alpha-\mathrm{Al}_{2} \mathrm{O}_{3}$ nanofluids. The founding are in agreement with results obtained by Xie et al. for both $5 \% \mathrm{Fe}_{3} \mathrm{O}_{4}$-kerosene and $1 \% \mathrm{MgO}$-EG nanofluids over the temperatures ranging from $10{ }^{\circ} \mathrm{C}$ to $60{ }^{\circ} \mathrm{C}[47,48]$. They revealed that the effective thermal conductivity of both 5\% MgO-EG and $1 \%$ $\mathrm{Fe}_{3} \mathrm{O}_{4}$-kerosene nanofluids vary, while the $\left(k_{\text {eff }} / k_{f}\right)$ are almost constant. On contrary, Saleh et al. 
[19] recently and also some others [10, 19, 35, 44, 45] depict that the effective thermal conductivity ratio of nanofluids varies with increase in temperatures. Therefore, it can conclude that the effect of temperature on thermal conductivity ratio depends on the nanofluids characteristics. Figure 6 (a) and (b) show that the thermal conductivity of $\alpha-\mathrm{Al}_{2} \mathrm{O}_{3}$-glycerol nanofluids varies significantly with increasing of $\phi$ and decreasing of $d_{p}$ as well. For all the three nanofluids samples, the thermal conductivities ratio improved up to $19.5 \%, 16.6 \%$ and $9.5 \%$ for $\mathrm{Al}_{2} \mathrm{O}_{3}-\alpha$ nanoparticle volume fraction of $4 \%$ for $31 \mathrm{~nm}, 55 \mathrm{~nm}$ and $134 \mathrm{~nm}$ size nanoparticles, respectively at $20^{\circ} \mathrm{C}$.

\subsubsection{Stability of $\alpha-\mathrm{Al}_{2} \mathrm{O}_{3}$-glycerol nanofluids}

Figure 7 shows the stability of the $\alpha-\mathrm{Al}_{2} \mathrm{O}_{3}$-glycerol nanofluids evaluated for $4 \%$ volume fraction. Thirty minutes after sonication, the effective thermal conductivity was acquired for all three nanoparticles sizes at 1 hour step, up to 50 hours. The t-statistic of the slope of the model (Eq. 10) of effective thermal conductivity of the model vs. elapsed time after preparation is 0.175 . The R-square and $\mathrm{p}$-value of both the $\mathrm{F}$ and $\mathrm{t}$ statistics are 0.000 and 0.861 (> 0.05), respectively. The variation of effective thermal conductivity of the model vs. elapsed time after preparation is not statistically justified. There is no dependence of $k_{e f f}$ of the model with elapsed time up to 50 hours. The best model is the naïve model, which is the mean value of $k_{e f f}$. The mean values and standard deviation are $0.335 \pm 0.002 \mathrm{~W} / \mathrm{mK}, 0.331 \pm 0.001 \mathrm{~W} / \mathrm{mK}$ and $0.304 \pm 0.001 \mathrm{~W} / \mathrm{mK}$ for $31 \mathrm{~nm}, 55 \mathrm{~nm}$ and $134 \mathrm{~nm}$, respectively.

$k_{\text {eff }}=0.323-3.66 \times 10^{-9} t$

where $t$ is elapsed time in second.

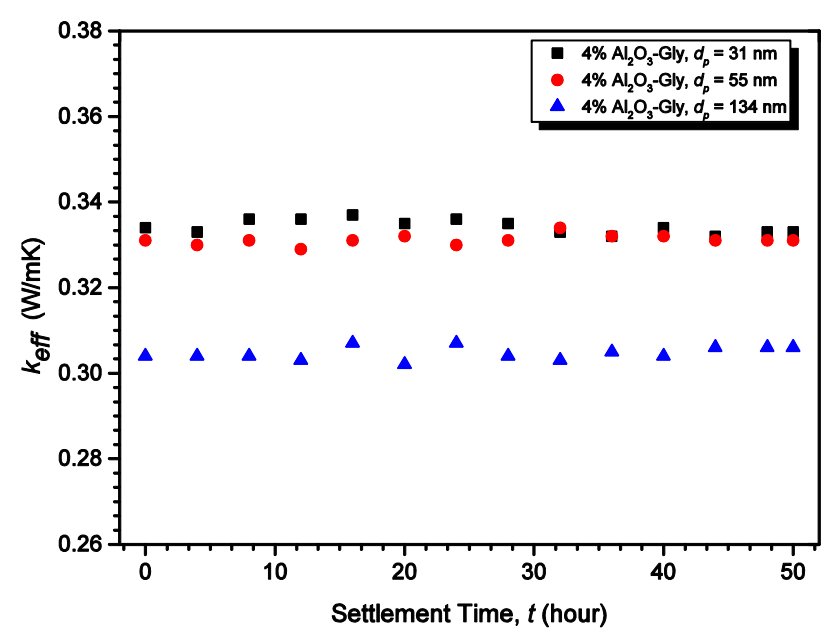

Figure 7: Influence of Settlement time on the Effective thermal conductivity of $4 \% \alpha-\mathrm{Al}_{2} \mathrm{O}_{3^{-}}$ glycerol nanofluids

The possible explanation of no enhancement of thermal conductivity of $\alpha-\mathrm{Al}_{2} \mathrm{O}_{3}$-glycerol nanofluids in the early hours after sonication could be the no clustering and settling of nanoparticles [41, 47, 49, 50]. 
The effective thermal conductivity measurement indicates the stability of $\alpha-\mathrm{Al}_{2} \mathrm{O}_{3}$-glycerol nanofluids at room temperature for at least 50 hours after preparation.

\subsection{Comparison of the thermal conductivity models with experimental data}

\subsubsection{Existing theoretical and empirical models}

Numerous studies, both experimental and theoretical, have been conducted to estimate the effective thermal conductivity of different nanofluids [51]. Several mathematical models of effective thermal conductivity of nanofluids have been proposed. This section presents the comparisons between the experimental data of $\alpha-\mathrm{Al}_{2} \mathrm{O}_{3}$-glycerol nanofluids and predictions from some existing theoretical models. Maxwell [52] offered the first and simple model of effective thermal conductivity for micro or millimetre sized spherical particles suspended in base fluids as follows:

$\frac{k_{e f f}}{k_{f}}=\frac{k_{p}+2 k_{f}+2\left(k_{p}-k_{f}\right) \phi}{k_{p}+2 k_{f}+\left(k_{p}-k_{f}\right) \phi}$

where $k_{p}, k_{f}$ and $\phi$ are the thermal conductivity of particle, the thermal conductivity of the base fluid, and the volume fraction of suspension, respectively. Maxwell's formula (Eq. 11) gives a good result for well-dispersed non-interacting spherical-shaped particles with low particle volume concentrations (less than 1\% [51]) and negligible thermal resistance at the particle-fluid interface.

Shaker et al. [53] recently proposed an extended Maxwell model as Eq. (12) for the thermal conductivity of nanofluids. They modify the classical model of Maxwell by taking into account for the nonlocal heat transfer rising due to the small characteristic length in nanofluids. The non colinearity parameter $(h)$ is determined by comparison between the novel model predictions and the experimental data of each given nanofluids. They depicted that $h$ is equal to 8 and 11 for alumina-EG and aluminawater nanofluids, respectively. The model is valid for spherical nanoparticles suspended in base fluid and can be modified to account also for not spherical nanoparticles suspension.

$\frac{k_{e f f}}{k_{f}}=\frac{1+2 \xi \phi \hbar^{-3}}{1-\xi \phi \hbar^{-3}}$

with

$$
\begin{aligned}
& \xi=\frac{k_{p}-k_{f}}{3\left(\mathfrak{J} 1 k_{p}-\mathfrak{J} 2 k_{f}\right)} \\
& \Im 1=\frac{1}{\hbar}+\arctan (\hbar)-\frac{\pi}{2}
\end{aligned}
$$

$$
\Im 2=\arctan (\hbar)+\frac{\hbar}{1+\hbar^{2}}+\frac{8 \hbar}{\left(1+\hbar^{2}\right)^{2}}+\frac{8 \hbar^{3}}{\left(1+\hbar^{2}\right)^{3}}-\frac{\pi}{2}
$$


$\hbar=\frac{r}{h}$

Aybar et al. [54] reported the Bruggeman correlation which is implicit formula for the effective thermal conductivity of spherical particles randomly distributed in the base fluid. The model is based on the differential effective medium (DEM) theory to estimate the effective thermal conductivity of composites at low and high particle volume concentrations. The model predicts good match with some experiment results for low and high solid concentration when the particle size is not a concern. This model gives the same result as the Maxwell model provides for low solid concentration, while the effect of size has not considered.

$$
\phi\left(\frac{k_{p}-k_{e f f}}{k_{p}+2 k_{e f f}}\right)+(1-\phi)\left(\frac{k_{f}-k_{e f f}}{k_{f}+2 k_{e f f}}\right)=0
$$

R.S. Vajjha and D.K. Das [39] offer a relation which is an improvement of the Koo and Kleinstreuer model derived from a broader set of data (133 data points), obtained from three nanofluids, viz. $\mathrm{Al}_{2} \mathrm{O}_{3}$, $\mathrm{CuO}$ and $\mathrm{ZnO}$ prepared with a mixture of water and 60:40 (by mass) ethylene. The model incorporates the classical Maxwell model and the Brownian motion effect to account for the thermal conductivity of nanofluids as a function of temperature, particle volumetric concentration, the properties of the nanoparticles and the base fluid. The applicable range is at temperature of 298-363 K and 29-77 nm for the particle size, respectively. The proposed equation is

$$
k_{e f f}=k_{e f f, \text { Maxwell }}+5 \times 10^{4} \epsilon \phi \rho_{p} c_{p f} \sqrt{\frac{\kappa T}{\rho_{p} d_{p}} f(T, \phi)}
$$

where the function $f(T, \phi)$ in Eq. (19) is the same for all three nanofluids as:

$f(T, \phi)=\left(2.8217 \times 10^{-2} \phi+3.917 \times 10^{-3}\right)\left(\frac{T}{T_{0}}\right)-\left(3.0669 * 10^{-2} \phi+3.91123 \times 10^{-3}\right)$

The $\epsilon$ correlation is the same for $\mathrm{Al}_{2} \mathrm{O}_{3}$ and $\mathrm{ZnO}$ but differs for $\mathrm{CuO}$ :

$$
\begin{array}{cl}
\epsilon=8.4407(100 \phi)^{-1.07304} & \text { (20) } \text { for }_{\mathrm{Al}_{2} \mathrm{O}_{3} \text { for } 1 \%<\phi<10 \% \quad \text { and } \mathrm{ZnO} \text { for } 1 \%<\phi<7 \% ;} \\
\epsilon=9.881(100 \phi)^{-0.9446} & \text { (21) for } \mathrm{CuO} \text { for } 1 \%<\phi<6 \%
\end{array}
$$

The effective medium equation [38] which introduce as Eq. (22), predicts the thermal conductivity ratio for highly conducting spherical particles. In the model, the particles are assumed to be immobile which cannot be realistic.

$k_{e f f}=[1+3 \phi] k_{f}$ 
Corcione [55] developed an empirical correlation as Eq. (23) for predicting the thermal conductivity ratio from experimental data, consisting of alumina, copper oxide, titania and copper nanoparticles suspended in water or ethylene glycol (EG). The correlation is valid for nanoparticle in the range of temperatures $21-51^{\circ} \mathrm{C}$, volume fraction $2-9 \%$ and nanoparticle diameter $10-150 \mathrm{~nm}$. The correlation was obtained by the way of regression analysis with a $1.86 \%$ standard deviation of error. The water and EG thermal conductivity are $0.598 \mathrm{~W} / \mathrm{m} .{ }^{\circ} \mathrm{C}$ and $0.237 \mathrm{~W} / \mathrm{m} .{ }^{\circ} \mathrm{C}$, respectively at $20{ }^{\circ} \mathrm{C}$. The glycerol thermal conductivity is $0.2837 \mathrm{~W} / \mathrm{m} .{ }^{\circ} \mathrm{C}$, which is between them $[23,24]$. Thus, the $k_{\text {eff }}$ of Glycerol based nanofluids may predict by Corcione correlation.

$$
\frac{k_{e f f}}{k_{f}}=1+4.4 \operatorname{Re}_{p}^{0.4} \operatorname{Pr}_{f}^{0.66}\left(\frac{T}{T_{f r}}\right)^{10}\left(\frac{k_{p}}{k_{f}}\right)^{0.66}
$$

where $R e_{p}$ is the nanoparticle Reynolds number, $\operatorname{Pr}_{f}$ is the Prandtl number of the base fluid, $T$ is the nanofluid temperature, $T_{f r}$ is the freezing point of the base liquid in Kelvin, $k_{p}$ is the nanoparticle thermal conductivity and $\phi$ is the volume fraction of the suspended nanoparticles.

with

$R e=\frac{2 \rho_{f} \kappa T}{\pi \mu_{f} d_{p}}$

$\operatorname{Pr}=\frac{\mu_{f} C_{p f}}{k_{f}}$

Li and Peterson [56] developed a correlation by linear regression analysis for predicting the thermal conductivity of $\mathrm{Al}_{2} \mathrm{O}_{3}$-distilled water nanofluids. The $\mathrm{Al}_{2} \mathrm{O}_{3}$ nanoparticles of the average diameter of $36 \mathrm{~nm}$ were mixed with water at volume fraction range of $2 \%$ to $10 \%$ for $\mathrm{Al}_{2} \mathrm{O}_{3}$ and temperature range of $28.9{ }^{\circ} \mathrm{C}$ to $33.4{ }^{\circ} \mathrm{C}$. They depicted that the particle volume fraction dependence of the effective thermal conductivity is much higher than the temperature dependence as well as the volume fraction dependence is more pronounced with increasing temperature.

$\frac{\left(k_{e f f}-k_{f}\right)}{k_{f}}=0.764481 \phi+0.018688867 T-0.462147175$

\subsubsection{Comparison between existing models and experimental data}

Figure 8 provides the comparison of the predicted effective thermal conductivity ratio from various models (Maxwell, Bruggeman, Effective medium theory, Vajjha et al., Li and Peterson, Corcione and Shaker) with experimental data of three sizes of $\alpha-\mathrm{Al}_{2} \mathrm{O}_{3}$-glycerol nanofluids versus volume fraction at room temperature. Li and Peterson model under-predictn the experimental data of $31 \mathrm{~nm}$ and $55 \mathrm{~nm} \alpha-$ $\mathrm{Al}_{2} \mathrm{O}_{3}$-glycerol nanofluids whereas Vajjha et al. model over-predicts range for $\phi<4 \%$ (see Figure 8 
(a) and (b)). Corcione model shows a slight increase of TCR with $\phi$ compared the experimental data. However, the increasing $\phi$ results in the diversion of Corcione model from experimental data. The other models give a good match to experimental data for $\phi<2 \%$. Figure 8 (c) discloses more or less similar results as exposed in Figure 8 (a) and (b), with the exception of both Shaker models, Maxwell, $\mathrm{Li}$ and Peterson, Bruggeman and Effective medium model are slightly higher than the experimental data of $134 \mathrm{~nm} \alpha-\mathrm{Al}_{2} \mathrm{O}_{3}$-glycerol nanofluids for $\phi>2 \%$.

Figure 9 (a), (b) and (c) present a comparison of the predicted TCR versus temperature for the selected models with experimental data of $31 \mathrm{~nm}, 55 \mathrm{~nm}$ and $134 \mathrm{~nm} \alpha-\mathrm{Al}_{2} \mathrm{O}_{3}$-glycerol nanofluids prepared at $4 \%$ volume fraction. Corcione model under-predicts the experimental results of the three $\alpha-\mathrm{Al}_{2} \mathrm{O}_{3^{-}}$ nanofluids. Li and Peterson model give good results for temperature for a part of temperature range (between $25{ }^{\circ} \mathrm{C}$ to $30{ }^{\circ} \mathrm{C}$ for $134 \mathrm{~nm}$ and between $30{ }^{\circ} \mathrm{C}$ to $35^{\circ} \mathrm{C}$ for $31 \mathrm{~nm}$ and $55 \mathrm{~nm}$ ). Vajjha model gives good predictions for temperature less than $30^{\circ} \mathrm{C}$ for $31 \mathrm{~nm}$ and temperature more than $35^{\circ} \mathrm{C}$ for $55 \mathrm{~nm}$. However, all the three previous models increase with the temperature rise disagreeing with the expected trend. The other models follow the expected trend and predict values that are lower than the experimental data for both $31 \mathrm{~nm}$ and $55 \mathrm{~nm}$ and greater than the experimental data for $134 \mathrm{~nm}$.
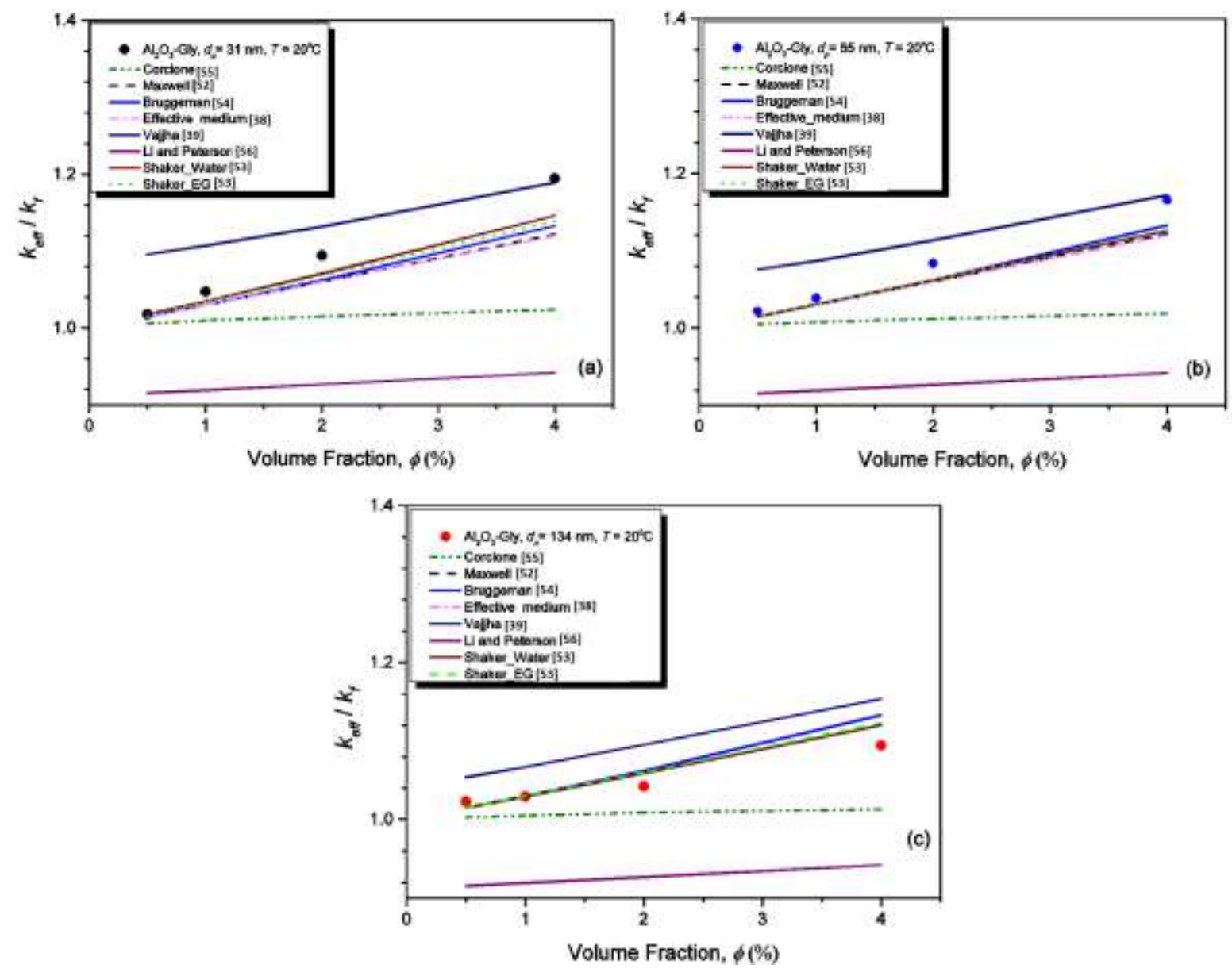

Figure 8: Comparison of the thermal conductivity ratio variation with volume fraction between the predictions form selected models and experimental data for $\alpha-\mathrm{Al}_{2} \mathrm{O}_{3}$-glycerol nanofluids at $20^{\circ} \mathrm{C}$ : (a) $31 \mathrm{~nm}$, (b) $55 \mathrm{~nm}$ and (c) $134 \mathrm{~nm}$ 
Figure 10 provides comparisons of the predicted TCR versus diameter relationship for the selected models with experimental data sets of $\alpha-\mathrm{Al}_{2} \mathrm{O}_{3}$-glycerol nanofluids prepared at $4 \%$ volume fraction. Corcione underestimate the experimental data set while Vajjha model overestimate. The TCR of $\alpha$ $\mathrm{Al}_{2} \mathrm{O}_{3}$-glycerol nanofluids agrees well with the prediction of Maxwell, Bruggeman and effective medium, but their trend is contrary to the expected one. Li and Peterson model overestimated the TCR for the three nanofluids. Its pattern is dissimilar to the experimental data trend.

Although the prediction of certain selected models are partially within the acceptable range of experimental data of $\alpha-\mathrm{Al}_{2} \mathrm{O}_{3}$-glycerol nanofluids for the various involved parameters, (see Figure 8 , Figure 9 and Figure 10), but the models trend didn't follow the expected trend for each analyzed parameter (temperature, size and volume fraction) while the models underpredict or overpredict the experimental data or the model trend doesn't follow the data pattern.
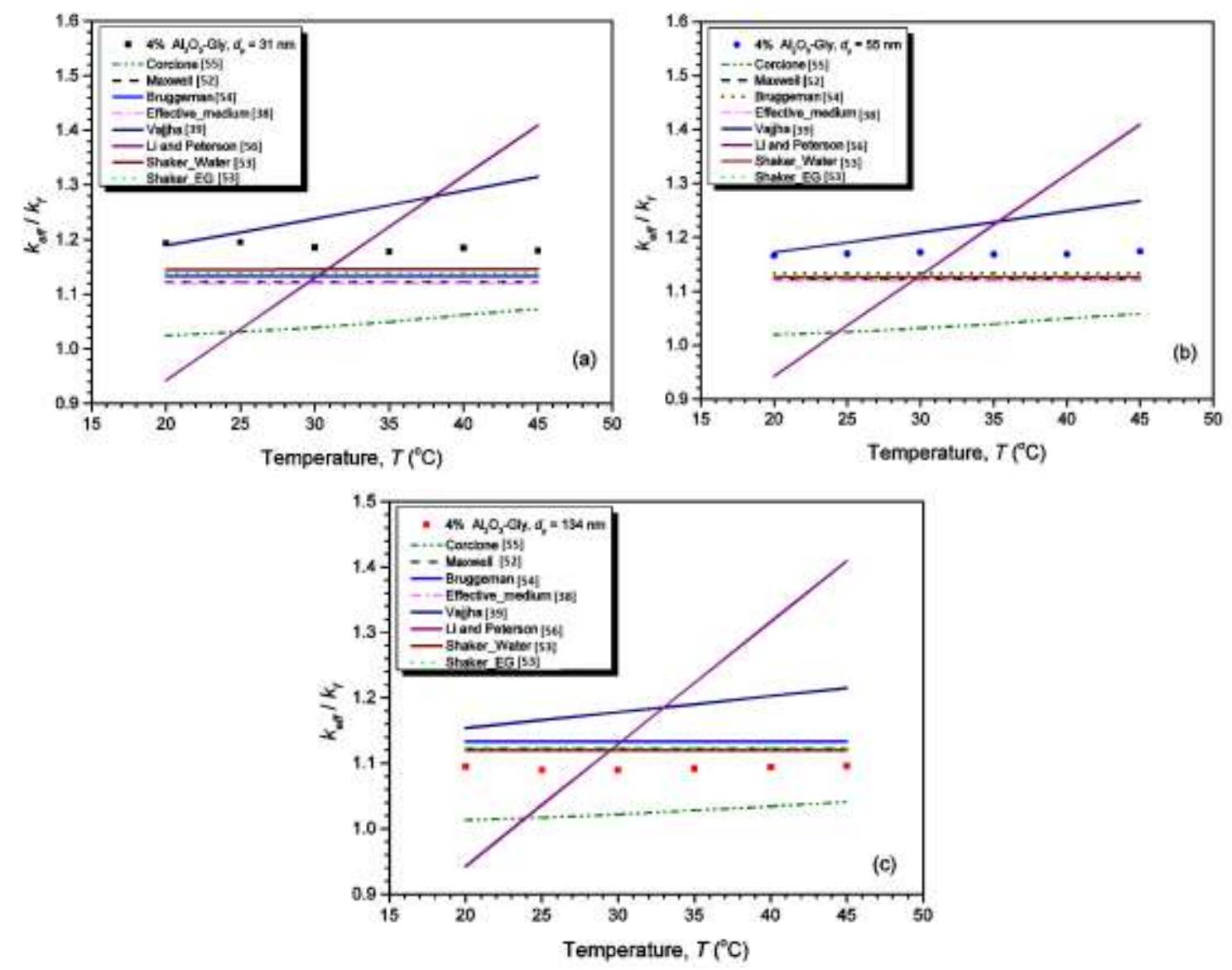

Figure 9: Comparison of thermal conductivity ratio variation with temperature between the predictions form selected models and experimental data for $4 \% \alpha-\mathrm{Al}_{2} \mathrm{O}_{3}$-glycerol nanofluids: (a) $31 \mathrm{~nm}$, (b) $55 \mathrm{~nm}$ and (c) $134 \mathrm{~nm}$ 


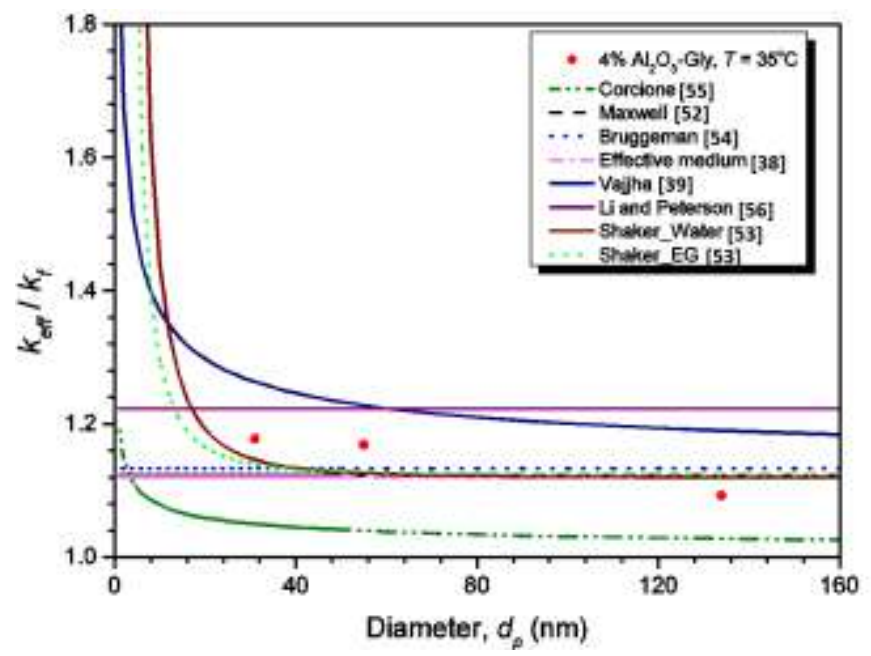

Figure 10: Comparison of thermal conductivity ratio variation with nanoparticle diameter between the predictions form selected models and experimental data for $4 \% \alpha-\mathrm{Al}_{2} \mathrm{O}_{3}$-glycerol nanofluids at $35^{\circ} \mathrm{C}$

\subsubsection{New empirical correlation for the thermal conductivity ratio of $\alpha-\mathrm{Al}_{2} \mathrm{O}_{3}$-glycerol nanofluids}

A new empirical correlation is derived from the experimental data on $\alpha-\mathrm{Al}_{2} \mathrm{O}_{3}$-glycerol nanofluids over the temperature range $20{ }^{\circ} \mathrm{C}$ to $45{ }^{\circ} \mathrm{C}$, concentration range $0.5 \%$ to $4 \%$ and particle sizes $\left(d_{p}\right)$ ranging from $31 \mathrm{~nm}$ to $134 \mathrm{~nm}$. The novel equation is a modified version of Corcione model [55]. The relationship between the TCR (dependent variable) and the independent variables are statistically verified by regression analysis [33]. Eq. (27) is the developed empirical correlation for $\alpha-\mathrm{Al}_{2} \mathrm{O}_{3^{-}}$ glycerol nanofluid.

$\frac{k_{e f f}}{k_{f}}=1+R e_{p}^{0.4377} \operatorname{Pr}_{f}^{0.9400} \phi^{1.0475}\left(\frac{k_{p}}{k_{f}}\right)^{0.6661}$

where $k_{p}$ is the thermal conductivity of the $\alpha-\mathrm{Al}_{2} \mathrm{O}_{3}$ nanoparticles (equal to $40 \mathrm{~W} / \mathrm{mK}$ ). The others parameters are defined in section 3.4.1.

Equation (27) has unadjusted R-square $=0.980, \mathrm{~F}=3.7 * 10^{5}$ and significant $\mathrm{p}=0.0000$. The $\mathrm{t}$-statistic of $R e_{p}, P r_{f}, \phi$ and $k_{p} / k_{f}$ exponents are 19.4, 20.3, 38.5 and 16.1, respectively. Their associated pvalues are highly significant $(\mathrm{p}<0.001)$. No colinearity exists between exploratory parameters as their variance inflation factor $(\mathrm{VIF})<10$. However, the $\mathrm{p}$-value of the independent term of the equation and the exponents of both Prandtl number and temperature were not statistically significant in the general Corcione model. After exclusion of the temperature term $\left(T / T_{f r}\right)$, the multicollinearity remains due to high linear correlation $(\mathrm{R}=0.9992)$ between the $k_{p} / k_{f}$ and the independent terms of the equation. The comparison between the predicted TCR from the new correlation and the experimental data shows an excellent agreement with maximum relative error of $-2.37 \%$, and the average relative error of - 
$0.03 \%$ (see Figure 11). Also, the residual sum is zero and there is no autocorrelation in the residuals. The offered analysis provides evidence that the new model is statistically significant.

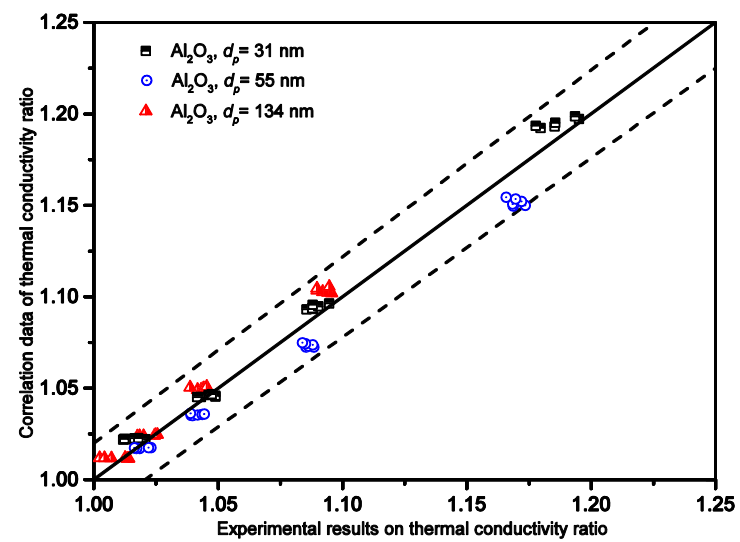

Figure 11: Comparison of the thermal conductivity ratio between the predicted values from the new correlation and the experiments data on $\alpha-\mathrm{Al}_{2} \mathrm{O}_{3}$-glycerol nanofluids

Figure 12 depicts the impact of temperature on the three standardized parameters of the novel equation for $\alpha-\mathrm{Al}_{2} \mathrm{O}_{3}$-glycerol nanofluid. The standardized parameters are Reynolds number term $R e^{0.4377}$, Prandtl number term $\operatorname{Pr}^{0.9400}$ and thermal conductivity of nanoparticle normalised to the thermal conductivity of glycerol term $\left[k_{p} / k_{f}\right]^{0.6661}$. Figure 12 discloses that the standardised $\operatorname{Pr}$ decreases with a rise in temperature while the standardized Re increases and standardized term $k_{p} / k_{f}$ is almost unchanged. The magnitude of $P r$ term is much larger compared to combined Re and standardized $k_{p} / k_{f}$ terms. The normalized $\operatorname{Pr}$ is the major parameter describing the enhancement of TCR of $\alpha$ $\mathrm{Al}_{2} \mathrm{O}_{3}$-glycerol nanofluids, as opposed to the Reynold number for the case of $\mathrm{Al}_{2} \mathrm{O}_{3}$-water nanofluid [57]. The described phenomenon strengthens the TCR with the rise of volume fraction of suspended $\alpha$ $\mathrm{Al}_{2} \mathrm{O}_{3}$ nanoparticle in the glycerol.
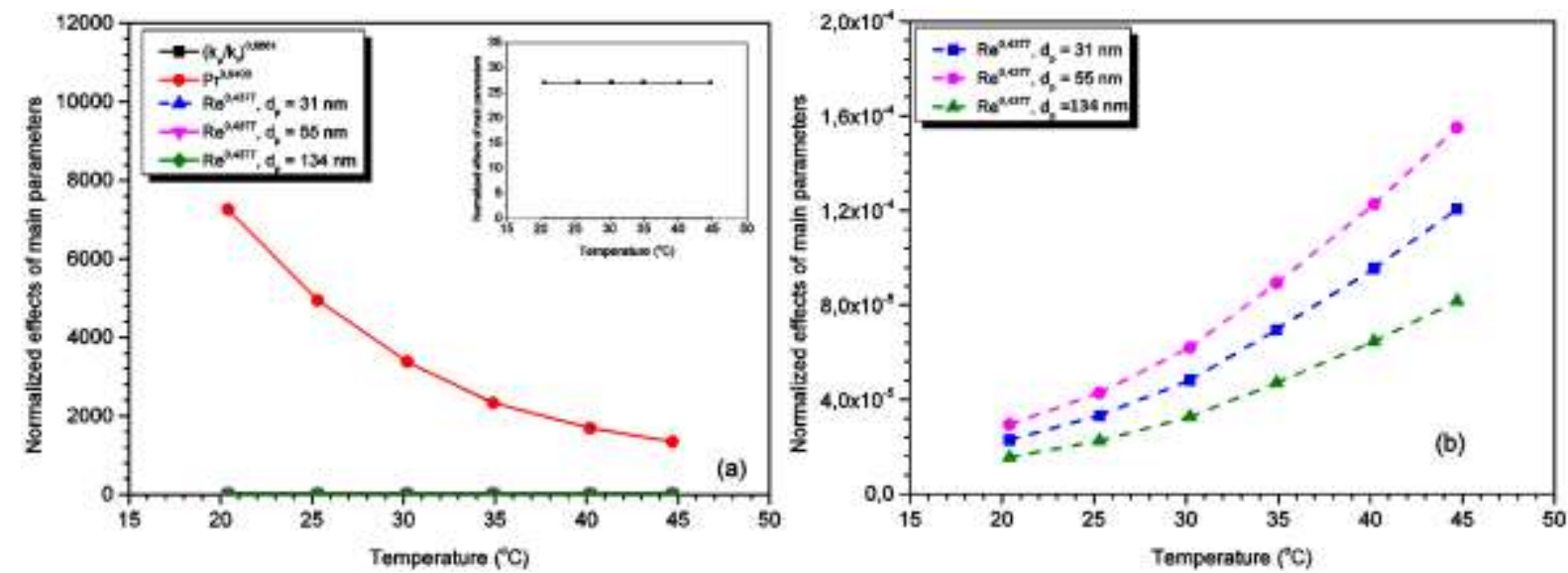

Figure 12: Temperature dependence of the effects of the novel correlation of $1 \%$ volume fraction $\alpha-\mathrm{Al}_{2} \mathrm{O}_{3}$-glycerol nanofluids of (a) the three parameters of (b) $R e$ parameters 


\section{Conclusion}

The following findings are drawn from the experimental results and discussions on the thermal conductivity of $\alpha-\mathrm{Al}_{2} \mathrm{O}_{3}$-glycerol nanofluids:

1. The addition of $\alpha-\mathrm{Al}_{2} \mathrm{O}_{3}$ nanoparticles to glycerol (base fluid) enhances the effective thermal conductivity of glycerol. However, the effective thermal conductivity of nanofluid tracks the base fluid, but shifted.

2. The thermal conductivity ratio increases linearly with volume fraction of $\alpha-\mathrm{Al}_{2} \mathrm{O}_{3}$ nanoparticles at a constant temperature. It is unchanged with temperature variation. The TCR decreases with increasing of nanoparticle's size under the condition of the same volume fraction and temperature.

3. The $\alpha-\mathrm{Al}_{2} \mathrm{O}_{3}$-glycerol nanofluids prepared without any surfactants can stay stable for at least 50 hours after preparation.

4. The Prandtl number is the major parameter describing the enhancement of TCR of $\alpha-\mathrm{Al}_{2} \mathrm{O}_{3^{-}}$ glycerol nanofluids, not the Reynold number. The impact of Brownian diffusion is minor compared to the thermal diffusion in the thermal conductivity enhancement of the $\alpha-\mathrm{Al}_{2} \mathrm{O}_{3^{-}}$ glycerol nanofluids.

5. The predictions from models in the literature are partially within the acceptable range of experimental data for the various involved parameters, but either didn't follow the expected pattern for each analyzed parameter (temperature, size and volume fraction) or are not consistent in all conditions.

6. Therefore, a new empirical correlation has been developed.

\section{Acknowledgements}

The authors from University of Pretoria, gratefully acknowledge the funding obtained from Energy IRT Seed-funding (2014-EIRTSharifpur).

\section{References}

[1] R.M. Mostafizur, M.H.U. Bhuiyan, R. Saidur, A.R. Abdul Aziz, Thermal conductivity variation for methanol based nanofluids, International Journal of Heat and Mass Transfer, 76 (2014) 350-356.

[2] K.S. Suganthi, K.S. Rajan, A formulation strategy for preparation of ZnO-Propylene glycol-water nanofluids with improved transport properties, International Journal of Heat and Mass Transfer, 71 (2014) 653-663.

[3] A.N. Al-Shamani, M.H. Yazdi, M. Alghoul, A.M. Abed, M. Ruslan, S. Mat, K. Sopian, Nanofluids for improved efficiency in cooling solar collectors-A review, Renewable and Sustainable Energy Reviews, 38 (2014) 348-367. 
[4] M.J. Pastoriza-Gallego, L. Lugo, D. Cabaleiro, J.L. Legido, M.M. Piñeiro, Thermophysical profile of ethylene glycol-based $\mathrm{ZnO}$ nanofluids, The Journal of Chemical Thermodynamics, 73 (2014) 2330.

[5] H. Xie, W. Yu, Y. Li, L. Chen, Discussion on the thermal conductivity enhancement of nanofluids, Nanoscale Research Letters, 6(1) (2011) 1-12.

[6] V. Bianco, O. Manca, S. Nardini, K. Vafai (Eds.), Heat Transfer Enhancement with Nanofluids, CRC Press, Boca Raton Fl, USA, 2015, ISBN 9781482254006.

[7] K. Khanafer, K. Vafai, A critical synthesis of thermophysical characteristics of nanofluids, Int. J. Heat Mass Transf. 54 (2011) 4410-4428.

[8] B. Buonomo, O. Manca, L. Marinelli, S. Nardini, Effect of temperature and sonication time nanofluid thermal conductivity measurements by nano-flash method, Applied Thermal Engineering, 91, (2015) 181-190.

[9] J. Lee, K. Han, J. Koo, A novel method to evaluate dispersion stability of nanofluids, International Journal of Heat and Mass Transfer, 70 (2014) 421-429.

[10] M. Ghanbarpour, E. Bitaraf Haghigi, R. Khodabandeh, Thermal properties and rheological behavior of water based $\mathrm{Al} 2 \mathrm{O} 3$ nanofluid as a heat transfer fluid, Experimental Thermal and Fluid Science, 53 (2014) 227-235.

[11] L. Syam Sundar, E. Venkata Ramana, M.K. Singh, A.C.M. Sousa, Thermal conductivity and viscosity of stabilized ethylene glycol and water mixture Al2O3 nanofluids for heat transfer applications: An experimental study, International Communications in Heat and Mass Transfer, 56 (2014) 86-95.

[12] ASTM, Proposed ASTM Engine Coolant Standards Focus on Glycerin, 2010. Available: http://www.astmnewsroom.org/default.aspx?pageid=2115. [Online, accessed: 14 April 2014].

[13] SDA, Glycerine-An Overview, The Soap and Detergent Association, Glycerine and Oleochemical Division, 1990. Available: www.aciscience.org/docs/glycerine_-_an_overview.pdf. [Online, accessed: 14 April 2014].

[14] Y. Li, J.e. Zhou, S. Tung, E. Schneider, S. Xi, A review on development of nanofluid preparation and characterization, Powder Technology, 196(2) (2009) 89-101.

[15] U.R. Nanomaterials, Nanopowder: Single-Element Oxides (Al2O3 alpha, 99+\%, 80 nm), US Research Nanomaterials, 2014. Available: http://www.us-nano.com/nanopowders. [Online, accessed: 14 April 2014].

[16] MKNano, Nanoparticles: Single-Element-Oxides/Aluminum Oxide Nanopowder (Al2O3-Alpha, 40 nm, 99.5\% Pure \& Al2O3-Alpha, 100 nm, 99.9\% Pure), MKNano, 2014. Available: http://mknano.com/Nanoparticles/Single-Element-Oxides/. [Online, accessed: 14 April 2014].

[17] S.I. Jeol, JEM-2100F Transmission Electron Microscope, JOEL USA, 2015. Available: http://www.jeolusa.com/PRODUCTS/TransmissionElectronMicroscopes\%28TEM\%29/200kV/JEM2100F/tabid/208/Default.aspx. [Online, accessed: 6 March 2015]. 
[18] D. Devices, KD2 Pro thermal properties analyzer operator's manual version 4, in, Decagon Devices, Inc., Pullman, WA, USA, 2015, pp. 1-67.

[19] R. Saleh, N. Putra, R.E. Wibowo, W.N. Septiadi, S.P. Prakoso, Titanium dioxide nanofluids for heat transfer applications, Experimental Thermal and Fluid Science, 52 (2014) 19-29.

[20] B.H. Salman, H.A. Mohammed, K.M. Munisamy, A.S. Kherbeet, Characteristics of heat transfer and fluid flow in microtube and microchannel using conventional fluids and nanofluids: A review, Renewable and Sustainable Energy Reviews, 28 (2013) 848-880.

[21] U.T. Hielscher, UP200H / UP200S - Ultrasonic Power for the Lab, hielscher ultrasonics gmbh 2014. Available: http://www.hielscher.com/200s_p.htm. [Online, accessed: 14 April 2014].

[22] Lauda, Operating instructions: ECO GOLD Heating and cooling thermostat with control head Gold in: 08/2011a1, Lauda Dr. R. Wobser GM BH \& CO.KG, 2011, pp. 1 - 119.

[23] G.F. Hewitt, Heat Exchanger Design Handbook 2008: Physical properties, Begell house, New York, USA, 2008, pp. 5.5.10-71.

[24] F.P. Incropera, D.P. DeWitt, Introduction to Heat Transfer, John Wiley \& Sons, New York, USA, 1996, pp. 836-844.

[25] S. Horiba, A guidebook to particle size analysis, in, HORIBA Instruments, Irvine, CA, USA, 2012, pp. 1-32.

[26] N.R. Dhineshbabu, G. Karunakaran, R. Suriyaprabha, P. Manivasakan, V. Rajendran, Electrospun MgO/Nylon 6 Hybrid Nanofibers for Protective Clothing, Nano-Micro Letters, 6(1) (2014) 46-54.

[27] V. Baecker, Workshop: Image processing and analysis with ImageJ and MRI Cell Image Analyzer, Montpellier RIO Imaging, 2010. Available:

http://www.mri.cnrs.fr/datas/fichiers/articles/60/183.pdf. [Online, accessed: 5 May 2014].

[28] C. Suryanarayana, M.G. Norton, X-ray Diffraction: A Practical Approach, Plenum Publishing Corporation, New York, USA, 1998, pp. 207-221.

[29] A. Garbout, S. Bouattour, A.B. do Rego, A. Ferraria, A. Kolsi, Synthesis, Raman and X-ray diffraction investigations of rubidium-doped $\mathrm{Gd} 1.8 \mathrm{Ti} 2 \mathrm{O} 6.7$ pyrochlore oxide via a sol-gel process, Journal of Crystal Growth, 304(2) (2007) 374-382.

[30] C. Oprea, V. Ciupina, G. Prodan, Investigation of nanocrystals using TEM micrographs and electron diffraction technique, Roumania Journal of Physics, 53(1-2) (2008) 223-230.

[31] S.A. Speakman, Estimating Crystallite Size Using XRD, MIT Center for Materials Science and Engineering, 2012. Available: www.eng.uc.edu/ beaucag/Classes/.../MITCrystalSizeAnalysis.pdf. [Online, accessed: 10 March 2014].

[32] R.S. Figliola, D.E. Beasley, Theory and design for mechanical measurements, 5th ed., John Wiley \& Sons, USA, 2011, pp. 161-198.

[33] D.G.K. Kleinbaum, Lawrence L.; Nizam, Azhar ; Muller, keith E., Applied Regression Analysis and Other Multivariate Methods, 4e ed., Thomson Higher education Belmont, USA, 2008, pp. 305 348. 
[34] H.J. Berendsen, A student's guide to data and error analysis, Cambridge University Press, 2011, pp. 84-106.

[35] S. Halelfadl, T. Maré, P. Estellé, Efficiency of carbon nanotubes water based nanofluids as coolants, Experimental Thermal and Fluid Science, 53 (2014) 104-110.

[36] I.M. Mahbubul, S.A. Fadhilah, R. Saidur, K.Y. Leong, M.A. Amalina, Thermophysical properties and heat transfer performance of Al2O3/R-134a nanorefrigerants, International Journal of Heat and Mass Transfer, 57(1) (2013) 100-108.

[37] W. Duangthongsuk, S. Wongwises, Measurement of temperature-dependent thermal conductivity and viscosity of TiO2-water nanofluids, Experimental Thermal and Fluid Science, 33(4) (2009) 706714.

[38] E. Timofeeva, A. Gavrilov, J. McCloskey, Y. Tolmachev, S. Sprunt, L. Lopatina, J. Selinger, Thermal conductivity and particle agglomeration in alumina nanofluids: Experiment and theory, Physical Review E, 76(6) (2007) 1-16.

[39] R.S. Vajjha, D.K. Das, Experimental determination of thermal conductivity of three nanofluids and development of new correlations, International Journal of Heat and Mass Transfer, 52(21-22) (2009) 4675-4682.

[40] M. Kole, T.K. Dey, Effect of prolonged ultrasonication on the thermal conductivity of $\mathrm{ZnO}-$ ethylene glycol nanofluids, Thermochimica Acta, 535 (2012) 58-65.

[41] R.S. Khedkar, S.S. Sonawane, K.L. Wasewar, Influence of CuO nanoparticles in enhancing the thermal conductivity of water and monoethylene glycol based nanofluids, International Communications in Heat and Mass Transfer, 39(5) (2012) 665-669.

[42] Y. Xuan, Heat transfer enhancement of nanofuids, International Journal of Heat and Fluid Flow, 21 (2000) 58-64.

[43] T.-P. Teng, Y.-H. Hung, T.-C. Teng, H.-E. Mo, H.-G. Hsu, The effect of alumina/water nanofluid particle size on thermal conductivity, Applied Thermal Engineering, 30(14-15) (2010) 2213-2218.

[44] K.S. Suganthi, K.S. Rajan, Temperature induced changes in $\mathrm{ZnO}-$ water nanofluid: zeta potential, size distribution and viscosity profiles, International Journal of Heat and Mass Transfer, 55(25) (2012) 7969-7980.

[45] S.M.S. Murshed, K.C. Leong, C. Yang, Investigations of thermal conductivity and viscosity of nanofluids, International Journal of Thermal Sciences, 47(5) (2008) 560-568.

[46] M. Kole, T.K. Dey, Thermophysical and pool boiling characteristics of $\mathrm{ZnO}$-ethylene glycol nanofluids, International Journal of Thermal Sciences, 62 (2012) 61-70.

[47] H. Xie, W. Yu, W. Chen, MgO nanofluids: higher thermal conductivity and lower viscosity among ethylene glycol-based nanofluids containing oxide nanoparticles, Journal of Experimental Nanoscience, 5(5) (2010) 463-472.

[48] W. Yu, H. Xie, L. Chen, Y. Li, Enhancement of thermal conductivity of kerosene-based Fe3O4 nanofluids prepared via phase-transfer method, Colloids and Surfaces A: Physicochemical and Engineering Aspects, 355(1-3) (2010) 109-113. 
[49] M.-S. Liu, M.C.-C. Lin, C.Y. Tsai, C.-C. Wang, Enhancement of thermal conductivity with Cu for nanofluids using chemical reduction method, International Journal of Heat and Mass Transfer, 49(17-18) (2006) 3028-3033.

[50] K.S. Hong, T.-K. Hong, H.-S. Yang, Thermal conductivity of Fe nanofluids depending on the cluster size of nanoparticles, Applied Physics Letters, 88(3) (2006) 1-3.

[51] M. Sharifpur, T. Ntumba, J.P. Meyer, Parametric analysis of effective thermal conductivity models for nanofluids, in: Proceedings of the ASME 2012 International Mechanical Engineering Congress and Exposition, American Society of Mechanical Engineers, Houston, USA, 2012, pp. 1-11.

[52] J. Buongiorno, D.C. Venerus, N. Prabhat, T. McKrell, J. Townsend, R. Christianson, Y.V. Tolmachev, P. Keblinski, L.-w. Hu, J.L. Alvarado, I.C. Bang, S.W. Bishnoi, M. Bonetti, F. Botz, A. Cecere, Y. Chang, G. Chen, H. Chen, S.J. Chung, M.K. Chyu, S.K. Das, R. Di Paola, Y. Ding, F. Dubois, G. Dzido, J. Eapen, W. Escher, D. Funfschilling, Q. Galand, J. Gao, P.E. Gharagozloo, K.E. Goodson, J.G. Gutierrez, H. Hong, M. Horton, K.S. Hwang, C.S. Iorio, S.P. Jang, A.B. Jarzebski, Y. Jiang, L. Jin, S. Kabelac, A. Kamath, M.A. Kedzierski, L.G. Kieng, C. Kim, J.-H. Kim, S. Kim, S.H. Lee, K.C. Leong, I. Manna, B. Michel, R. Ni, H.E. Patel, J. Philip, D. Poulikakos, C. Reynaud, R. Savino, P.K. Singh, P. Song, T. Sundararajan, E. Timofeeva, T. Tritcak, A.N. Turanov, S. Van Vaerenbergh, D. Wen, S. Witharana, C. Yang, W.-H. Yeh, X.-Z. Zhao, S.-Q. Zhou, A benchmark study on the thermal conductivity of nanofluids, Journal of Applied Physics, 106(9) (2009) 1-14.

[53] M. Shaker, E. Birgersson, A. Mujumdar, Extended Maxwell model for the thermal conductivity of nanofluids that accounts for nonlocal heat transfer, International Journal of Thermal Sciences, 84 (2014) 260-266.

[54] H. Ş. Aybar, M. Sharifpur, M. R. Azizian, M. Mehrabi, and J. P. Meyer, A Review of Thermal Conductivity Models of Nanofluids, Heat Transfer Engineering, 36 (13) (2015) 1085-1110, 2015.

[55] M. Corcione, Empirical correlating equations for predicting the effective thermal conductivity and dynamic viscosity of nanofluids, Energy Conversion and Management, 52(1) (2011) 789-793.

[56] C.H. Li, G.P. Peterson, Experimental investigation of temperature and volume fraction variations on the effective thermal conductivity of nanoparticle suspensions (nanofluids), Journal of Applied Physics, 99(8) (2006) 1-8.

[57] C.H. Chon, K.D. Kihm, S.P. Lee, S.U.S. Choi, Empirical correlation finding the role of temperature and particle size for nanofluid ( $\mathrm{Al} 2 \mathrm{O} 3$ ) thermal conductivity enhancement, Applied Physics Letters, 87(15) (2005) 1-3. 